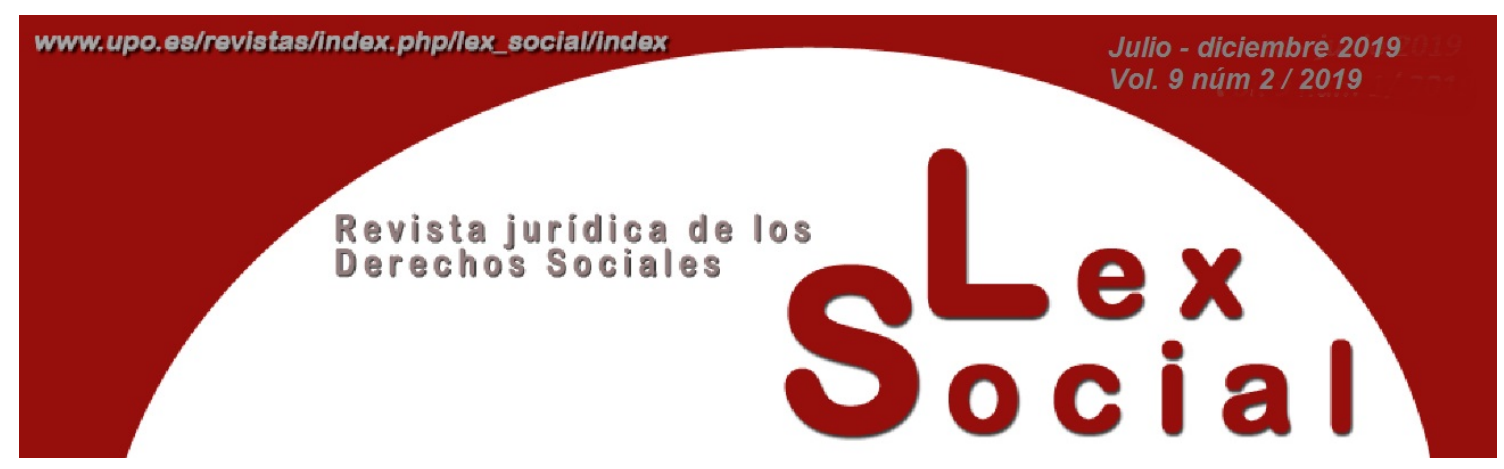

\title{
DE SIRVIENTAS A TRABAJADORAS: \\ LA NECESARIA RATIFICACION DEL CONVENIO 189 OIT SOBRE TRABAJO DECENTE PARA LAS TRABAJADORAS Y LOS TRABAJADORES DOMESTICOS
}

\section{FROM SERVANTS TO WORKERS: \\ THE NECESSARY RATIFICATION OF THE ILO CONVENTION 189 ON DECENT WORK OF DOMESTIC WORKERS}

CARMEN GRAU PINEDA

Titular (TU) de Derecho del Trabajo y de la Seguridad Social

Universidad de Las Palmas de Gran Canaria

Artículo recibido el 4 de abril de 2019

Artículo aceptado el 27 de mayo de 2019

\section{RESUMEN}

La regulación española del trabajo doméstico se debate entre la aceptación pacífica y sosegada de unos aspectos y la inacción político-legislativa frente a otros que resultan más conflictivos por razones diversas. Recién aprobado el Convenio 189, por allá por junio de 2011, era generalizado no dudar ni de la oportunidad de la norma y de su necesidad y justicia, ni del éxito de su ratificación. Sea como fuere, a día de hoy España no ha ratificado el Convenio 189 pese a haber dado los primeros pasos para adecuar su normativa interna nada más aprobarse en mismo y antes de que entrara en vigor. Da la sensación de tratarse de un Convenio que ha caído en el olvido y que, salvo la insistencia recurrente del todavía incipiente movimiento asociativo, ha sido imbuida por una desidia que imposibilita la necesaria acción política. Que España podría haber ratificado el Convenio 189 desde el día siguiente a su aprobación y haber llevado a cabo las modificaciones/adaptaciones normativas precisas sin solución de 
continuidad, nadie lo pone en duda. Pero no se ha optado por esa posibilidad y, en estos momentos de impasse, conviene insistir en que la ratificación del Convenio 189, además de ser una cuestión de justicia social, es importante también en términos económicos y de seguridad social.

PALABRAS ClAVE: Cuidados, trabajo doméstico, trabajo decente, derechos humanos, perspectiva de género, feminización, precarización, economía informal, España.

\section{ABSTRACT}

The Spanish regulation of domestic work is torn between the peaceful and calm acceptance of some aspects and the political-legislative inaction against others that are more conflictive for different reasons. Having recently approved Convention 189, back in June 2011, it was generalized not to doubt either the timeliness of the norm and its necessity and justice, or the success of its ratification. However, today Spain has not ratified Convention 189 despite having taken the first steps to adapt its internal regulations as soon as it was approved and before it entered into force. It gives the sensation of being an agreement that has fallen into oblivion and that, except for the recurrent insistence of the still incipient associative movement, has been imbued with a laziness that precludes the necessary political action. That Spain could have ratified Convention 189 from the day after its approval and have carried out the precise modifications/adaptations of regulations without continuity solution, nobody doubts it. But this possibility has not been chosen and, in these moments of impasse, it is important to insist that the ratification of Convention 189, besides being a matter of social justice, is also important in terms of economic and social security.

KEY WORDS: care jobs, domestic work, decent work, human rights, gender perspective, feminization, precarization, informal economy, Spain.

SUMARIO

1. EL RECONOCIMIENTO DEL TRABAJO DOMESTICO Y DE CUIDADOS COMO EJE VERTEBRADOR DE LA NUEVA GENERACION DE NORMAS SOCIOLABORALES 
1.1. Un poco de historia y algunas cifras para la reflexión: de la vieja a la nueva generación de normas sobre el trabajo doméstico.

1.2. El debate económico: Crisis económica y crisis de cuidados.

1.3. La traslación al debate jurídico-normativo.

2. EL CONVENIO 189 DE LA OIT SOBRE TRABAJO DECENTE PARA LAS TRABAJADORAS Y LOS TRABAJADORES DOMESTICOS.

2.1. La igualdad de género como nueva acción normativa preferente a nivel mundial.

2.2. Los diversos enfoques nacionales sobre la regulación del trabajo doméstico.

3. LA REGULACIÓN ESPAÑOLA DEL TRABAJO DOMÉSTICO: el "misterio" de la no ratificación del Convenio 189.

3.1. Las posibles razones (I): entre la tradición y la etnización.

3.2. Las posibles razones (II): entre reticencias superables y resistencias infranqueables.

4. ALGUNAS REFLEXIONES FINALES.

5. BIBLIOGRAFIA

“Mientras las mujeres no gocen de empoderamiento económico y social en el mundo laboral, en el hogar y la comunidad el crecimiento no será inclusivo y no lograremos erradicar la pobreza. La creación de sociedades inclusivas y pacíficas seguirá fuera de nuestro alcance hasta que las mujeres y las niñas estén a salvo de toda forma de violencia y puedan influir en las decisiones que afectan a su vida ${ }^{1}$ ”.

\section{EL RECONOCIMIENTO DEL TRABAJO DOMESTICO Y DE CUIDADOS COMO EJE VERTEBRADOR DE LA NUEVA GENERACION DE NORMAS SOCIO-LABORALES}

El estudio del servicio doméstico conduce a una inequívoca primera conclusión, su endémica discriminación y desprotección social, la cual ha perdurado a través de las diversas épocas manteniéndose incluso en la actualidad. Los últimos veinte años han

\footnotetext{
${ }^{1}$ GUTERRES, A.: "Prólogo", en ONU MUJERES: Hacer las promesas realidad: La igualdad de género en la Agenda 2030 para el desarrollo sostenible, ONU, 2018. Disponible en http://www.unwomen.org/es/digital-library/publications/2018/2/gender-equality-in-the-2030-agenda-forsustainable-development-2018\#view
} 
sido positivos para la situación de la mujer en el mundo del trabajo y la igualdad de género en la sociedad y eso nadie la pone en duda. No obstante, pese al progreso logrado hasta ahora y al empeño en seguir avanzando, las perspectivas de la mujer en el mundo del trabajo distan mucho de ser iguales a las de los hombres ${ }^{2}$. Allí donde persisten los problemas y obstáculos que impiden la participación de la mujer en igualdad de condiciones, la sociedad tendrá menos capacidad para trazar una vía hacia el crecimiento económico y social. En consecuencia, la comunidad mundial tiene ante sí uno de los retos socio-laborales más acuciantes: subsanar las brechas de género en el mundo del trabajo.

En la última década, gobiernos, empleadores y trabajadores, han adoptado una serie de medidas para solucionar los problemas que afrontan las mujeres en el mundo del trabajo. Cabe destacar especialmente el avance en el ámbito de la asistencia a la familia, la formalización de esferas fundamentales del trabajo informal con predominio femenino (como el trabajo doméstico) y las iniciativas para resolver la segregación horizontal y vertical por razones de género, en especial en esferas en las que las reformas pueden reducir la discriminación basada en el género. Pero las iniciativas actuales de los principales actores del mercado de trabajo para reducir la desigualdad en el mercado laboral entre mujeres y hombres muestran no estar siendo suficientes y "la diferencia de acceso de unas y otros entorpece mucho las iniciativas mundiales destinadas a lograr un mercado laboral más justo e inclusivo ${ }^{3}$ ".

Del trabajo doméstico y de cuidados se ha dicho que es "un lugar privilegiado para analizar la recreación de las desigualdades de género (...), un punto estratégico desde el que cuestionar la perversidad de un sistema económico que niega la responsabilidad social en la sostenibilidad de la vida y cuyo mantenimiento precisa de la exclusión y la invisibilidad -heterogénea y multidimensional- de múltiples colectivos sociales ${ }^{4 »}$. Temática que nos sitúa, de lleno, en la desigualdad material que persiste en el mundo del trabajo. El trabajo doméstico y de cuidados -que engloba tanto las tareas del hogar como los cuidados interpersonales- está infravalorado por considerarse "improductivo" dado que no genera beneficios económicos directos o utilidades para los hogares que los emplean. Entre las razones principales de esta infravaloración, la falta de consideración como actividad económica -no computa ni en las estadísticas, ni en las estimaciones del PIB, ni en la formulación de políticas públicas-, pero también la inexistencia de una demanda de habilidades y cualificación específica. Pero, sobre todo, los prejuicios. Un estudio sobre los salarios en la economía del cuidado en comparación mundial

\footnotetext{
${ }^{2}$ En general, véase OIT: Perspectivas sociales y del empleo en el mundo: tendencias del empleo femenino 2018, OIT, 2018.

${ }^{3}$ Ídem, p. 13.

${ }^{4}$ PEREZ OROZCO, A.: “Amenaza tormenta: la crisis de los cuidados y la reorganización del sistema económico”, Revista de Economía Crítica, n 5, 2006, p. 31.
} 
publicado en la Revista Internacional del Trabajo en $2010^{5}$ lleva a la conclusión de que “el trabajo de cuidado no está menos remunerado porque sea menos cualificado, (...) no está peor remunerado debido a que las personas que lo efectúan acepten salarios más bajos porque les guste hacerlo, (...) está infravalorado por ser un “trabajo femenino”, ya que si se considera las segregación por sexo en las ocupaciones las minusvaloraciones se reducen”. Y concluyen considerando que "mejorar los salarios de los trabajadores del cuidado servirá para asegurar que este personal entregado y cualificado siga atendiendo unos servicios que son decisivos para el mantenimiento de una sociedad sana ${ }^{6 ”}$.

Desde la economía feminista, para la que el trabajo doméstico y de cuidados viene siendo un tema central en las últimas cuatro décadas, se apunta que "designar por trabajo a la actividad desarrollada en el mercado y conceptualizar como no-trabajo a aquella realizada en los hogares, ha contribuido a consolidar una valoración distinta tanto para la actividad, como para las personas que la realizan. (...) La economía, al preocuparse solo del mercado y relegar al limbo de lo invisible el trabajo doméstico y de cuidados, está eludiendo toda responsabilidad sobre las condiciones de vida de la población, que continúa siendo una cuestión embarazosa para la teoría económica 7 ". Por eso, dos afirmaciones cruciales de la economía feminista son "que la economía no es reductible a los mercados, sino que economía es mantener la vida, sea o no a través de las esferas monetarizadas (...) [y] que el género funciona como elemento organizador del sistema económico, por tanto, es necesario atender a las relaciones de género para poder comprender la estructura socioeconómica"”.

Hoy en día, afortunadamente, a diferencia del sesgo androcéntrico de los modelos económicos habituales, los nuevos enfoques económicos que desde la economía feminista se defienden “(...) ofrecen una visión más realista de la sociedad, permitiendo el análisis de las interrelaciones entre los distintos sectores -monetarios y no monetarios- de la economía (...) [y] representa[n] (...) una ruptura con lo establecido desplazando los objetivos desde el beneficio empresarial al cuidado de la vida humana. Hacer explícito el trabajo doméstico y de cuidados en los esquemas económicos como trabajo necesario, no es solo una cuestión de justicia, sino de sensatez y rigor si se pretende analizar e interpretar la realidad ${ }^{9}$ ”. Y es que, es preciso tener en cuenta, como señala la OIT, que las contribuciones realizadas por el trabajo doméstico remunerado respecto de la disminución las tasas de pobreza y desempleo en un país tienen un valor económico, el cual se incrementa cuando son decentes los salarios percibidos por el

\footnotetext{
${ }^{5}$ BUDIG, M.J. Y MISRA, J.: "Los salarios de la economía del cuidado en comparación internacional”, Revista Internacional del Trabajo, vol. 129, nº 4, 2010, p. 508.

${ }^{6}$ Ídem, p. 509.

${ }^{7}$ CARRASCO, C.: “La economía del cuidado: planteamiento actual y desafíos pendientes", Revista de Economía Crítica, nº 11, 2011, p. 208.

${ }^{8}$ PEREZ OROZCO, A.: "Amenaza tormenta: la crisis de los cuidados y la reorganización del sistema económico”, op. cit., p. 9.

${ }^{9}$ CARRASCO, C.: "La economía del cuidado: planteamiento actual y desafíos pendientes”, op. cit., pp. 211-212.
} 
trabajo doméstico y las condiciones bajo las cuales se realiza. Pero es que, además, estas contribuciones se podrían ver, entre otras, como avances en el derecho al trabajo y los derechos socio-económicos en general ${ }^{10}$.

Inmersos como estamos en el Siglo XXI, se sigue considerando que tanto lo doméstico como los cuidados son cosa de mujeres y un asunto que debe resolverse dentro de la familia, siendo difícil encontrar países en los que haya más instituciones, aparte de las familiares, implicadas en su prestación. Y ello porque la desigualdad de género en la división del trabajo doméstico y de cuidados es un déficit generalizado, con independencia de la región del mundo, del nivel de ingresos o de las características culturales de que se trate. Si algo demuestran las encuestas sobre el uso del tiempo (allá donde las haya) es que las mujeres dedican más tiempo que los hombres al trabajo doméstico y de cuidados poniendo de manifiesto la brecha de género ${ }^{11}$ existente al respecto. Tampoco se libran de esta concepción países europeos, como España o Portugal, en los que la noción de los cuidados está estrechamente unida a la de la familia y el Estado tiene un papel muy reducido en la prestación de servicios formales de cuidado infantil o de mayores.

Las consecuencias de todo ello son obvias: las mujeres como principales prestadoras de servicios domésticos y proveedoras de los cuidados intrafamiliares tienen una capacidad menor para acceder a un trabajo remunerado que les permita, entre otras cosas, salir de la pobreza, gozar de independencia económica y generar pensiones como la de jubilación. Y es que como declaró la Conferencia Internacional del Trabajo en 2002, "la dificultad de reducir los déficit de trabajo decente es mucho mayor cuando el trabajo realizado está al margen del ámbito o campo de aplicación de los marcos jurídicos e institucionales ${ }^{12}$ ". Precisamente por ello tanto la legislación como las políticas reguladoras son instrumentos esenciales en pos de la eliminación de los aspectos negativos de la informalidad en un sector como el que nos ocupa, al tiempo que

10 Más detalles en OIT: Medición del valor económico y social del trabajo doméstico, Nota de información 3, OIT.

${ }^{11}$ El concepto de brecha(s) de género radica en la idea de que un lado de la brecha representa el óptimo a alcanzar y el otro, el déficit. Así, es importante tener en cuenta que "aunque las mujeres están mayormente en el lado deficitario, en algunas brechas es a los hombres a los que les queda mucho por hacer para alcanzar la igualdad. Efectivamente, el tener una expresión que indique que los hombres están en el lado del déficit en el trabajo doméstico y de cuidados, puede dar una imagen más clara de las relaciones de género. AL nombrar el déficit masculino de cuidados de su hogar y de las personas que en el conviven "brecha de cuidados", identificamos un fenómeno (...) que carecía de un nombre que evidenciara la deuda a déficit que tienen los hombres en nuestras sociedades en el sostenimiento de la vida. Déficit que solo podrán llenar con su propio esfuerzo y dedicación, aunque, sin duda, ayudarían ciertos cambios estructurales", en DIAZ, C., JABBAZ, M., AGUADO, E. Y GONZALEZ, L.: "Las brechas de género: brecha de cuidados y brecha salarial y brecha de tiempo propio", en DIAZ MARTINEZ, C. Y SIMÓ-NOGUERA, C.X. (coord..): Brecha salarial y brecha de cuidados, Tirant humanidades, 2016, pp. 19-20.

12 OIT: Resolución relativa al trabajo decente y la economía informal, adoptada en la $90^{a}$ reunión de la Conferencia Internacional del Trabajo, Ginebra, 2002. 
aseguran que las oportunidades de empleo y trabajo decente que ofrece este sector no se vean comprometidas. La informalidad (y/o formalidad precarizada) es sinónimo de desprotección, de fraude laboral, de inestabilidad laboral y de trabajo sin derechos y con bajo nivel de retribuciones y, como acertadamente se ha señalado, "en estas condiciones de partida, no cabe duda que la informalidad en el trabajo se presenta como un auténtico obstáculo en el camino hacia el progreso social y económico ${ }^{13}$ ”.

Desde una perspectiva general, resulta comprensible el interés que tenemos las mujeres por modificar los roles históricos que nos sitúan en desventaja económica, laboral y social, máxime en un momento en el que el crecimiento exponencial en el mercado de trabajo ha generado, incluso, el replanteamiento de los modelos familiares y de la redistribución de las tareas reproductivas y productivas mismas. Desde la perspectiva de los tratados internacionales de derechos humanos -como el Pacto Internacional de Derechos Económicos, Sociales y Culturales, la Convención sobre la eliminación de todas las formas de discriminación contra la mujer, la Convención sobre los Derechos del Niño y la Convención sobre los Derechos de las Personas con Discapacidad- si bien las cuestiones de género han recibido, en general, menor atención que otros aspectos de los derechos humanos, más recientemente empiezan a establecerse obligaciones jurídicamente vinculantes que deberían inducir a los Estados a tratar esta cuestión. El marco internacional de derechos humanos, establecido por tratados como los mencionados, se complementa con normas en el ámbito laboral -derivadas de la OIT como única agencia "tripartita" de las naciones unidas en el mundo del trabajo- como el Convenio 156 sobre los trabajadores con responsabilidades familiares, el Convenio 183 sobre la protección de la maternidad o el Convenio 189 sobre las trabajadoras y los trabajadores domésticos al que ahora se dedican estas páginas.

Pero no es esta una cuestión nueva, contemporánea, ni mucho menos. Téngase en cuenta que el Preámbulo de la Constitución de la OIT (1919) ya estableció de forma nítida los objetivos de la Organización, cuyo centenario estamos celebrando: "Considerando que la paz universal y permanente sólo puede basarse en la justicia social; Considerando que existen condiciones de trabajo que entrañan tal grado de injusticia, miseria y privaciones para gran número de seres humanos, que el descontento causado constituye una amenaza para la paz y armonía universales; y considerando que es urgente mejorar dichas condiciones”. Ahora, pero siguiendo la senda marcada hace ya un siglo, la Agenda 2030 de Naciones Unidas ${ }^{14}$ que lleva por título "Transformar

13 LOPEZ AHUMADA, E.: “Trabajo informal, transición a la formalidad e inclusión social en Latinoamérica”, Revista de Estudios Latinoamericanos de Relaciones Laborales y Protección Social, nº 3, 2017, p. 13.

14 Aprobada por la Asamblea General de Naciones Unidas y dentro de la que se incardinan los 17 Objetivos de Desarrollo Sostenible y las 169 metas, conexas, de carácter integrado e indivisible que pretenden hacer realidad los derechos humanos de todas las personas y alcanzar la igualdad entre los géneros y el empoderamiento de todas las mujeres y niñas. Para ello ambos conjugan las tres dimensiones del desarrollo sostenible: económica, social y ambiental. Los nuevos Objetivos y metas entraron en vigor el 1 de enero de 2016 y tiene por objetivo guiar las decisiones a adoptar durante los próximos 15 años. 
nuestro mundo", sitúa el trabajo decente para todos en el centro de las políticas para un desarrollo y un crecimiento sostenible e inclusivo que garantice la paz permanente.

Así es como el trabajo decente se ha convertido en un objetivo universal y ha sido integrado en las más importantes declaraciones de derechos humanos, ampliamente reflejadas en la Agenda 2030, para la que el reconocimiento de los derechos al colectivo de trabajadoras domésticas o empleadas de hogar es uno de los pilares del desarrollo sostenible ${ }^{15}$. Sin embargo, tanto la inactividad política como la inhibición de los Estados a la hora de regular y financiar el trabajo doméstico contraviene sus obligaciones de derechos humanos ${ }^{16}$. En este sentido, es fundamental corregir los déficits y las desigualdades persistentes en el terreno del trabajo doméstico y de cuidados para lograr muchos otros objetivos, especialmente la erradicación de la pobreza y el hambre (ODS 1 y 2), la mejora de los resultados de salud, bienestar y aprendizaje (ODS 3 y 4), la igualdad de género (ODS 5), el trabajo decente y el crecimiento económico (ODS $8{ }^{17}$ ), así como la reducción de las desigualdades (ODS 10).

De la Agenda $2030^{18}$ se ha dicho que "constituye una propuesta de acción en favor de las personas, el planeta y la prosperidad, con un objetivo claro fortalecer la paz universal dentro de un concepto más amplio de la libertad. La misma integra los Objetivos de Desarrollo del Milenio, para conseguir lo que estos no lograron, y en ese camino no quiere dejar a nadie atrás ${ }^{19}$ ". La relevancia de la Agenda radica, además de en lo ambicioso de su contenido, en el alcance e importancia que pretende tener a nivel mundial y más allá de los intereses y prioridades nacionales. Los objetivos de desarrollo

Más detalles en https://www.un.org/sustainabledevelopment/es/2015/09/la-asamblea-general-adopta-laagenda-2030-para-el-desarrollo-sostenible/

${ }^{15}$ La Meta 5.4 insta a adoptar un conjunto de políticas para reconocer y valorar el trabajo doméstico y de cuidados no remunerado.

${ }^{16}$ Asamblea General de la ONU, 2013. En España hay quienes apuntan duramente cómo “el autismo de las administraciones respecto a la crisis de los cuidados se está viendo agravado recientemente por la apuesta de gestión liberal de la crisis sistémica...”, en EZQUERRA, S.: “Crisis de los cuidados y crisis sistémica: la reproducción como pilar de la economía llamada real”, Revista Investigaciones Feministas, vol. 2, 2011, p. 183. Y es que, para la autora, resulta innegable que los recortes y privatizaciones de los servicios sociales públicos, los ataques a los derechos sociales y laborales, así como los impactos de todos ellos sobre las mujeres, no son meros efectos colaterales de la actual crisis sistémica y su gestión política, sino que constituyen una de sus principales estrategias en su huida hacia adelante (p. 186).

17 El octavo objetivo de desarrollo sostenible tiene por rúbrica: "Promover el crecimiento económico sostenido, inclusivo y sostenible, el empleo pleno y productivo y el trabajo decente para todos”. Dentro del trabajo decente como objetivo de desarrollo sostenible se encuentran la proscripción del trabajo forzoso, formas contemporáneas de esclavitud, trata de seres humanos y peores formas de trabajo infantil. ${ }^{18}$ La Agenda para el desarrollo para después de 2015 fue aprobada por la Asamblea General de Naciones Unidas y dentro de la misma se incardinan los 17 Objetivos de Desarrollo Sostenible y las 169 metas, conexas, de carácter integrado e indivisible que pretenden hacer realidad los derechos humanos de todas las personas y alcanzar la igualdad entre los géneros y el empoderamiento de todas las mujeres y niñas. Para ello ambos conjugan las tres dimensiones del desarrollo sostenible: económica, social y ambiental.

${ }^{19}$ GARCIA SEDANO, T.: "La Meta 8.7 de Objetivo de Desarrollo Sostenible ${ }^{\circ}$ 8: Una aproximación al incumplimiento por parte del Reino de España”, en BLAZQUEZ AGUADO, E. M. ${ }^{\text {a }}$ (Dir.): Los ODS como punto de partida para el fomento de la calidad del empleo femenino, Dykinson, 2018, pp. 175-198. 
sostenible (en adelante $\mathrm{ODS}^{20}$ ), son aquellas pautas internacionales que le permiten a los Estados alinearse con el fin de que todos y todas tengan una constante de crecimiento y desarrollo ${ }^{21}$. Así las cosas, se han planteado para su cumplimiento en 2030 (y desde 2015), 17 objetivos, que son el resultado del análisis de situaciones que aquejan al mundo y que al ser identificadas de manera idónea se podrá trabajar conjuntamente en aras de avanzar en la mejora de la calidad de vida de las personas, en el desarrollo de las comunidades y por ende de los Estados. Dentro de esta nueva estrategia mundial, las mujeres por fin, y como no podía ser de otro modo, jugamos un papel destacado, al ser un foco de atención principal.

Por razón de la materia que nos ocupa, es el quinto de los objetivos de desarrollo sostenible planteados el que nos interesa. Lo primero que quiere destacarse es su rúbrica: “Igualdad de género”. Y es que, la igualdad entre los géneros no es solo un derecho humano fundamental, sino la base necesaria para conseguir un mundo pacífico, próspero y sostenible. La ONU parte de la premisa básica de que, primero, si se facilita la igualdad a las mujeres y niñas en el acceso a la educación, a la atención médica, a un trabajo decente, y una representación en los procesos de adopción de decisiones políticas y económicas, se estarán impulsando las economías sostenibles y las sociedades y la humanidad en su conjunto se beneficiarán al mismo tiempo y, segundo, si se establecen nuevos marcos legales sobre la igualdad de las mujeres en el lugar de trabajo y la erradicación de las prácticas nocivas sobre las mujeres es crucial para acabar con la discriminación basada en el género que prevalece en muchos países del mundo ${ }^{22}$.

El Objetivo de Desarrollo Sostenible 5 establece como metas las 6 siguientes:

5.1. Poner fin a todas las formas de discriminación contra todas las mujeres y las niñas en todo el mundo.

5.2. Eliminar todas las formas de violencia contra todas las mujeres y las niñas en los ámbitos público y privado, incluidas la trata y la explotación sexual y otros tipos de explotación.

5.3. Eliminar todas las prácticas nocivas, como el matrimonio infantil, precoz y forzado y la mutilación genital femenina.

\footnotetext{
${ }^{20}$ Los 17 objetivos de desarrollo sostenible son erradicar la pobreza y el hambre (objetivos 1 y 2) ; garantizar una vida sana, educación, agua y energía (objetivos 3, 4, 6 y 7); lograr la igualdad de género (objetivo 5); promover el crecimiento económico y el trabajo decente (objetivo 8); construir infraestructuras (objetivo 9); reducir las desigualdades entre todos los países (objetivo 10); buscar que las ciudades sean inclusivas y seguras (objetivo 11); asegurar el consumo sostenible (objetivo 12); establecer medidas urgentes para frenar el cambio climático, conservar los océanos y detener la pérdida de la biodiversidad (objetivo 13, 14 y 15); promover paz y justicia (objetivo 16); y fortalecer las alianzas para el desarrollo sostenible (objetivo 17).

${ }^{21}$ CARREÑO CONTRERAS, Y.Z.: "Los objetivos de desarrollo sostenibles y el trabajo de cuidados: el caso de las madres comunitarias en Colombia”, en BLAZQUEZ AGUADO, E. M (Dir.): Los ODS como punto de partida para el fomento de la calidad del empleo femenino, Dykinson, 2018, pp. 199-224.

${ }^{22}$ Más detalles en la web oficial https://www.un.org/sustainabledevelopment/es/gender-equality/
} 
5.4. Reconocer y valorar los cuidados y el trabajo doméstico no remunerados mediante servicios públicos, infraestructuras y políticas de protección social, y promoviendo la responsabilidad compartida en el hogar y la familia, según proceda en cada país.

5.5. Asegurar la participación plena y efectiva de las mujeres y la igualdad de oportunidades de liderazgo a todos los niveles decisorios en la vida política, económica y pública.

5.6. Asegurar el acceso universal a la salud sexual y reproductiva y los derechos reproductivos según lo acordado de conformidad con el Programa de Acción de la Conferencia Internacional sobre la Población y el Desarrollo, la Plataforma de Acción de Beijing y los documentos finales de sus conferencias de examen.

5.a Emprender reformas que otorguen a las mujeres igualdad de derechos a los recursos económicos, así como acceso a la propiedad y al control de la tierra y otros tipos de bienes, los servicios financieros, la herencia y los recursos naturales, de conformidad con las leyes nacionales.

5.b Mejorar el uso de la tecnología instrumental, en particular la tecnología de la información y las comunicaciones, para promover el empoderamiento de las mujeres.

5.c Aprobar y fortalecer políticas acertadas y leyes aplicables para promover la igualdad de género y el empoderamiento de todas las mujeres y las niñas a todos los niveles.

Repárese en la meta 5.4. y la referencia expresa al trabajo doméstico y de cuidados. Algo tan infrecuente que cuesta creerlo. $\mathrm{Y}$ es que entre las situaciones que fueron analizadas por los diferentes organismos internacionales de derechos humanos para ser incorporadas a los objetivos de desarrollo sostenible ${ }^{23}$, encontramos, cómo el trabajo doméstico y de cuidados es considerado uno de los indicadores más desiguales y generadores de una de las más elevadas brechas entre géneros. La novedad radica ahora en que lo que se propone es, de un lado, poner en valor el cuidado y el trabajo doméstico no remunerado reconociéndolo y conectándolo con la reducción de la carga asociada a éste con el fin de que las mujeres aumenten su productividad y dispongan de más tiempo. Pero también asociándolo a la redistribución del trabajo entre las mujeres y los hombres en el seno de la familia, así como entre ésta y otras instituciones dedicadas a la prestación de cuidados. Una estrategia dirigida a invertir en servicios de cuidados que contribuiría a la creación de nuevos empleos en el sector asistencial y a resolver la falta de oportunidades de empleo respecto de las mujeres que caracteriza a muchos países.

Sin embargo, es conveniente no perder de vista que, para ello, resulta crucial, primero,

${ }^{23}$ ONU MUJERES: Hacer las promesas realidad: La igualdad de género en la Agenda 2030 para el desarrollo sostenible, op. cit., p. 224. 
incorporar una perspectiva de género en la implementación y el seguimiento de todos los objetivos de desarrollo sostenible, porque la igualdad de género es crucial para esta visión transformadora como objetivo en sí mismo y como catalizador de los avances en toda la Agenda 203024; y, segundo, invertir en las infraestructuras de los cuidados para hacerlos extensivos a la otra mitad de la población, revirtiendo la asignación de roles de género que sostienen las desigualdades de hoy en día. La inversión pública en infraestructuras y servicios de cuidados no solo permite que las mujeres dispongan de más tiempo y mejora sus perspectivas laborales, sino que además puede fortalecer las capacidades de las personas receptoras de cuidados, generar oportunidades de empleo decente tanto para las mujeres como para los hombres a través de la ampliación de los cuidados y permitir trazar una trayectoria de crecimiento más inclusivo ${ }^{25}$.

No cabe más que congratularse por todo ello y aprovechar este gran impulso que ha generado el debate internacional respecto de la mercantilización del trabajo doméstico y de cuidados y la inclusión de una política de corresponsabilidad que incluya al Estado, la sociedad y la familia, para menguar las cargas a las que diariamente se ven sometidas las mujeres y de esta manera, permitir que las mismas puedan tener iguales oportunidades laborales que los hombres. Porque la práctica de cuidar no debería de tener género y porque "la solución pasa por promover un cambio real de paradigmas sociales donde la práctica de cuidar se convierta en el centro de las políticas sociales, haciéndose extensible a la otra mitad de la población. Hay que cambiar la ética del cuidado feminizada por la ética del cuidado humanizada, para caminar hacia una sociedad más pacífica e igualitaria. El cuidado y la asistencia no son asuntos de mujeres, sino intereses humanos universales. La violencia genera violencia, el cuidado genera cuidado ${ }^{26 ”}$.

\footnotetext{
${ }^{24}$ MLAMBO-NGCUKA, P.: "Prólogo", en ONU MUJERES: Hacer las promesas realidad: La igualdad de género en la Agenda 2030 para el desarrollo sostenible, op. cit.

${ }^{25}$ Nos parece obligada la referencia, siquiera somera, a Razavi introdujo la noción del "diamante de cuidado" como forma de estructurar el pensamiento de las instituciones que pueden dar atenciones o cuidados. Las cuatro puntas del diamante son la familia o el hogar, mercados, el sector público y el sector sin fines lucrativos. El concepto del diamante de cuidado es potencialmente útil para resaltar la medida en que el Estado considera las similitudes entre el trabajo de cuidado y el de los trabajadores domésticos remunerados lo suficientemente importantes para entregar estos servicios directamente, o subvencionar o financiar la provisión de tales servicios de una u otra manera. Allí donde el Estado lo hace, esto sugiere que el Estado le atribuye un valor significativo al trabajo. De este modo la provisión o financiamiento estatal se convierte en un indicador de valor. Razavi observa que el diamante de cuidado es particularmente pertinente cuando se considera el cuidado de niños jóvenes, ancianos delicados, personas con enfermedades crónicas o con discapacidad. Sin embargo, es difícil pensar en muchas circunstancias en las que el Estado, o incluso el sector sin fines lucrativos, pudiera ser el proveedor de servicios básicos del hogar. Se podrían entregar como parte de un paquete de apoyo a grupos específicos, como los ancianos o enfermos, pero sería muy inusual un Estado que introdujera políticas amplias para la provisión de labores del hogar. Más detalles en Razavi, S.: The political and social economy of care in a development context: Conceptual issues, research questions and policy options, Gender and Development Programme Paper No. 3 (Ginebra, Instituto de Investigación de las Naciones Unidas para el Desarrollo Social), 2007.

${ }^{26}$ POYATOS I MATAS, G.: "De la ética del cuidado feminizada a la ética del cuidado humanizada. A
} 


\subsection{Un poco de historia y algunas cifras para la reflexión: de la vieja a la nueva generación de normas sobre el trabajo doméstico}

En una aportación como ésta, nos parece obligado comenzar con un poco de historia y recordar que "tanto las prácticas de discriminación por motivos de género, raza u origen social como las raíces históricas del trabajo doméstico, que se hallan en la relación entre el señor y el criado, han influido en las actitudes y las prácticas sociales actuales respecto de los trabajadores domésticos, contribuyendo a definirlas, incluida la negación de los derechos laborales de que disfrutan los trabajadores de otros sectores económicos ${ }^{27}$ ”. Los derechos y las garantías de las trabajadoras domésticas han ido siempre a la zaga de los derechos y las garantías de que disfrutaban otros trabajadores, pudiendo considerarse uno de los colectivos más vulnerables ${ }^{28}$. La función llevada a cabo por las trabajadoras domésticas ha sido, desde siempre, inversamente proporcional a su valoración y protección, debido no solo a su invisibilidad y ausencia de proyección externa sino también por su particular vulnerabilidad. La propia OIT, en 1970, llegó a la conclusión de que "en su conjunto, la mayoría de trabajadores domésticos parecen estar sobrecargados de trabajo e insuficientemente remunerados y protegidos ${ }^{29}$ ”. Con el paso de los años, muchos países fueron adoptando legislación laboral sobre el trabajo doméstico, principalmente en Europa y América Latina, pero, en muchos casos, estas iniciativas se estancaron en la década de los ochenta del siglo pasado.

Más recientemente, se han promulgado una nueva generación de normas sobre trabajo doméstico en respuesta a las preocupaciones humanitarias, relacionadas con la igualdad de género y los derechos humanos, nueva generación de la que el Convenio 189 y la Recomendación 201 son sus máximos exponentes ${ }^{30}$. Julián Marías, en un largo ensayo

propósito de la cuestión prejudicial planteada por el Tribunal Superior de Justicia de Canarias respecto al “complemento por maternidad””, Revista de Trabajo y Seguridad Social, CEF, no 431, 2019, pp. 126-127. 27 OELZ, M.: “El Convenio y la Recomendación de la OIT sobre las trabajadoras y los trabajadores domésticos. Una oportunidad para la justicia social”, Revista Internacional del Trabajo, vol. 133, $\mathrm{n}^{\circ}$ 1, p. 162.

${ }^{28}$ Las trabajadoras domésticas son uno de los colectivos de trabajadores más vulnerables. El sector ha sido considerado tradicionalmente como el punto de acceso al mercado laboral para las comunidades poco cualificadas y desfavorecidas. El bajo estatus socioeconómico de las trabajadoras domésticas; el estigma de dicho trabajo, que es considerado en muchos países como una actividad no productiva; el tipo de lugar de trabajo aislado, y con una representación colectiva todavía escasa, hace que estos trabajadores sean particularmente vulnerables a la explotación y a las malas condiciones de trabajo.

${ }^{29}$ OIT: The employment and conditions of domestic workers in private households, documento D.11 1970 de la OIT, Ginebra, 1970. Disponible en http://www.ilo.org/public/libdoc/ ilo/1970/70B09_88_engl.pdf. En español, puede consultarse una versión resumida en "Situación y condiciones de empleo de los trabajadores domésticos en los hogares privados: Estudio de la OIT”, Revista Internacional del Trabajo, vol. 82, $\mathrm{n}^{\circ} 4$.

${ }^{30}$ No está de más insistir en el hecho de que este convenio recoge gran parte de los derechos establecidos en otros convenios OIT, pero aplicados al ámbito concreto del trabajo doméstico. Así, y sin ningún ánimo de exhaustividad al respecto, pueden referirse los convenios 29 (trabajo forzoso), 87 (libertad sindical), 97 y 143 (trabajadores migrantes), 98 (sindicación y negociación colectiva), 100 (igualdad remuneración), 105 (abolición trabajo forzoso), 111 (discriminación), 138 (edad mínima), 156 (trabajadores con 
en $1949^{31}$, afirmaba que "la marcha efectiva de la historia procede por generaciones". Y traemos esto a colación porque, esta nueva generación de normas sobre el trabajo doméstico responde, o eso pretende hacer, a la integración de la mujer al mundo del trabajo y el incremento de las tasas de actividad femenina, pero también del envejecimiento de la población mundial y del déficit en la prestación de servicios públicos de cuidado. El número de trabajadoras domésticas se ha incrementado en más de 20 millones y es probable que siga aumentando en los próximos años y el escaso desarrollo de políticas sociales para la conciliación de la vida familiar y laboral ha impedido una reorganización social de los actores destinados a la reproducción social y se ha generado la necesidad de soluciones alternativas entre las que la contratación de empleadas domésticas ha sido mayoritaria como refleja la curva ascendente que en las dos últimas décadas se observa en este sector.

La OIT publicó en 2012 una guía para la protección eficaz de los trabajadores domésticos que abunda en la necesidad de legislar en beneficio de este sector de la economía y contextualiza que "la participación cada vez mayor de las mujeres en la fuerza de trabajo, la intensificación del trabajo y la ausencia de políticas sociales eficaces que permitan el equilibrio entre la vida laboral y la familiar, han contribuido al aumento continuo de la demanda de trabajadores domésticos, poniendo en evidencia su importancia en la mayoría de los países desarrollados y en desarrollo ${ }^{32 " .}$

Aunque es difícil calcular exactamente la cantidad de trabajadores domésticos en el mundo, sobre todo porque forman parte de la economía informal, las estimaciones de la OIT para 2018 indicaban que existen al menos 67 millones de trabajadores domésticos en el mundo, sin incluir a los niños trabajadores domésticos, y esta cifra crece a un ritmo constante en todos los países. Pero lo que resulta una realidad innegable es la dependencia del trabajo doméstico realizado por terceras personas ajenas a los hogares como estrategia privada para contrarrestar las crecientes tensiones entre la vida laboral y familiar. Así, mientras unas mujeres se incorporan al mercado de trabajo, otras realizan el trabajo doméstico que aquellas no pueden afrontar en su integridad, pero de forma remunerada. Solo gracias a la existencia de las empleadas domésticas es que muchas madres trabajadoras han podido progresar en la economía productiva formal; sin embargo, las primeras no disfrutan de la protección necesaria para trabajar en condiciones decentes como si lo hacen las segundas ${ }^{33}$. En otras palabras, “la mujer tiene

responsabilidades familiares), 181 (agencias privadas de colocación) y 182 (peores formas de trabajo infantil).

31 Titulado El método histórico de las generaciones, Revista de Occidente, 1949.

32 OIT: Protección eficaz de los trabajadores domésticos: guía para diseñar leyes laborales, Ginebra, 2012, p. 2.

33 Como apunta el Profesor Antonio Baylos en su blog, "hablar del trabajo de las mujeres supone considerar dos grandes áreas, la del trabajo retribuido o remunerado, fundamentalmente por cuenta ajena, y la del trabajo donado o no retribuido, que sin embargo es fundamental para los cuidados que sostienen la vida misma, lo que se han denominado los “cuidados inmolados” que carecen de politicidad directa y 
una participación cada vez mayor en el mercado de trabajo, y el mantenimiento del hogar y el cuidado de los miembros de la familia dependen en mayor medida del trabajo doméstico remunerado. Al mismo tiempo, el trabajo doméstico es, por sí mismo, una fuente importante de empleos asalariados, en particular en el caso de mujeres con pocas

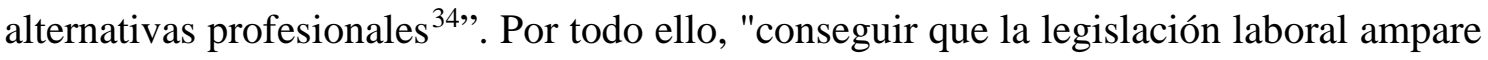
también a los trabajadores domésticos, en su gran mayoría mujeres y migrantes, es una cuestión de igualdad de género y de igualdad de protección ante la ley, en pocas palabras, una cuestión de derechos humanos ${ }^{35 "}$ ".

\subsection{El debate económico: La crisis económica y la crisis de cuidados}

Como es por todos sabido, los efectos de la última gran crisis mundial han sido muy distintos en los diferentes países. Pero, en lo que a nuestro interés va referido, quiere destacarse el hecho de que los efectos sobre mujeres y hombres han sido diferentes como resultado de que ni la situación de origen era similar ni las consecuencias de la crisis han sido las mismas para unas y otros. Y es que "mujeres y hombres tienen una vinculación muy diferente con el mercado laboral y tienen distintos grados de libertad a la hora de decidir su trabajo y sus posibilidades de empleo. (...) Cuando las mujeres se han ido incorporando al mercado lo han hecho ocupando empleos más precarios que los de los hombres (...) y tienen muchas más dificultades (...) para incorporarse a ello como consecuencia de su mayor dedicación al cuidado de la familia y sus miembros, y de las barreras culturales que han existido desde tiempos ancestrales a la hora de permitir que las mujeres dispongan de la libertad que pueda proporcionar la disposición autónoma de ingresos y capacidades de decisión ${ }^{36}$ ”. Con todo, es preciso tener en cuenta que "los ciclos económicos vienen y van, pero la desigualdad de género permanece, y todo ello, porque la diferencia de género, responde a factores fuertemente arraigados en el modelo de mercado de trabajo ${ }^{37}$ ". Lo que aplicado al actual contexto determina que el advenimiento de una recesión económica como la acontecida haya afectado en mayor medida a las mujeres "porque sus empleos son menos "valiosos” y precarios y porque, además, la norma social patriarcal dominante suele imponer que sean las mujeres las que se disponen a abandonar antes el trabajo para hacer frente a las nuevas demandas de cuidado familiar que suele plantear la recesión económica ${ }^{38 ” .}$

\footnotetext{
son invisibles para la representación dominante de los procesos sociales”, en http://baylos.blogspot.com/2019/03/el-trabajo-remunerado-de-las-mujeres-en.html

34 OELZ, M.: "El Convenio y la Recomendación de la OIT sobre las trabajadoras y los trabajadores domésticos. Una oportunidad para la justicia social”, op. cit., p. 163.

35 OIT: Protección eficaz de los trabajadores domésticos: guía para diseñar leyes laborales, op. cit., p. 3.

${ }^{36}$ GALVEZ MUÑOZ, G. Y TORRES LOPEZ, J.: Desiguales. Mujeres y hombres en la crisis financiera, Icaria, 2010, pp. 94 y ss.

37 SANZ SAEZ, C.: "La discriminación en contra de las empleadas de hogar como forma de manifestación de las discriminaciones múltiples”, Revista de Derecho Social, nº 83, 2018, pp. 105-106.

${ }^{38}$ GALVEZ MUÑOZ, G. Y TORRES LOPEZ, J.: Desiguales. Mujeres y hombres en la crisis financiera, op. cit., p. 99.
} 
En definitiva, crisis económica y crisis de cuidados coexisten temporalmente y, si bien la primera no es la única causante de la segunda, se retroalimentan. Y ello porque, de un lado, el momento de recesión económica general y generalizada a nivel mundial que está significando una redistribución salvaje de la renta y la riqueza pero, también, de los tiempos y los trabajos. Una crisis que, en definitiva, está repercutiendo de forma brutal directamente en las condiciones de vida de las personas dado que sus efectos están siendo durísimos para mucha gente pero, en particular, para las mujeres, como grupo social más vulnerable en una sociedad patriarcal. Según el reciente informe de la OIT sobre tendencias del empleo femenino $2018^{39}$ las exigencias abrumadoramente desiguales que pesan sobre las mujeres respecto de las responsabilidades domésticas y de atención continúan manifestándose como desigualdades en el mercado laboral en el tipo de puestos de trabajo disponibles para las mujeres y en los que pueden gozar de empleo duradero. De hecho, los problemas mundiales de informalidad y pobreza laboral están también arraigados en patrones de segregación sectorial y ocupacional por razón de género que limitan sistemáticamente las posibilidades de que la mujer pueda acceder a empleos mejores. Esto sugiere que la solución a los problemas del mercado laboral que afrontan las mujeres requerirá no solo el esfuerzo de los gobiernos, los empleadores y los sindicatos para eliminar las diferencias en el mercado de trabajo, sino también iniciativas que eliminen las exigencias desiguales que pesan sobre las mujeres. Para reducir las brechas entre los géneros en el mercado laboral se habrán de adoptar medidas integrales formuladas específicamente para las mujeres y que, en última instancia, contribuirán al bienestar de la sociedad.

Repárese en que la gestión neoliberal ${ }^{40}$ de la crisis sistémica manifestada desde 20072008, de un lado, ha agravado y cronificado la denominada “crisis de los cuidados” y ha mostrado la fragilidad de las respuestas ante ella ${ }^{41}$. En clave de género, la crisis

39 OIT: Perspectivas sociales y del empleo en el mundo: tendencias del empleo femenino 2018, OIT, 2018, p. 13.

${ }^{40}$ Téngase en cuenta, además, que el feminismo del siglo XXI o la cuarta oleada del feminismo surge frente al desarrollo de un neoliberalismo caracterizado por frenar los avances legislativos y de políticas públicas encaminados a conseguir la igualdad de derechos para las mujeres. En este sentido se ha dicho que "la discriminación de las mujeres en la etapa neoliberal y el hecho de que las políticas que se han llevado a cabo en estos últimos años hayan podido llevarse a cabo justamente en la medida en que esta discriminación se ha producido, son una muestra más (...) de la naturaleza contradictoria y finalmente destructora del neoliberalismo y de la globalización neoliberal que le ha servido de contexto. Se trata de una época histórica en la que la humanidad ha dispuesto de más recursos que nunca, de las mayores potencialidades para el desarrollo social que ha conocido el ser humano, lo que ha promovido logros inauditos, entre los que sin duda se encuentran los avances en la emancipación de millones de mujeres, aunque eso haya sido debido a su esfuerzo y al apoyo de los colectivos feministas que han servido como motor de esos cambios. Pero, al mismo tiempo, al basarse e una pauta distributiva tan desigual y en unos valores (entre los que los del patriarcado ocupan un lugar principal) tan reaccionarios, ha generado el efecto inverso: gran desigualdad, exclusión y segregación social también en el caso de muchos millones de mujeres, sobre todo a través de las cadenas globales de cuidado provocadas por la crisis del cuidad en los países ricos y su extensión a los más pobres”, en GALVEZ MUÑOZ, G. Y TORRES LOPEZ, J.: Desiguales. Mujeres y hombres en la crisis financiera, op. cit., pp. 63 y ss.

${ }^{41}$ EZQUERRA, S.: "Crisis de los cuidados y crisis sistémica: la reproducción como pilar de la economía llamada real”, op. cit., p. 176. 
económica está significando, entre otras cosas, una reprivatización de la reproducción social. Y ello porque, constatada una drástica reducción del gasto público en servicios de cuidados, sanitarios o educativos, la finalidad -no confesada- es que una parte de los cuidados regresen al hogar y sean asumidos por las mujeres y funcionen como amortiguador de los efectos devastadores de la crisis en el bienestar de las personas. En suma, la crisis de cuidados no es más que el "síntoma y resultado de la profundización de las tensiones-divisiones que el capitalismo patriarcal ocasiona y sobre las que se erige, entre privado y público, entre reproductivo y productivo $\mathrm{y}$, en última instancia, entre la satisfacción de las necesidades humanas y la generación de beneficio económico ${ }^{42 "}$. Ahora bien, conscientes de que "la crisis parece estar haciendo rebrotar conceptos sexistas de preferencia de conservación del trabajo para los hombres, infravalorando las necesidades económicas, profesionales y de autonomía personal de las mujeres ${ }^{43}$ ”, es de trascendental importancia tener muy presente que ofrece una valiosa oportunidad para poner de manifiesto no solo la importancia del cuidado y la reproducción como motor invisible de la economía sino "la opresión de género inherente a esta relación parasitaria entre ambas esferas ${ }^{44}$ ”.

Pero es que, de otro lado, conviene tener presente que las diversas transformaciones sociales, económicas, políticas y demográficas acontecidas en las últimas décadas, coincidentes con la crisis económica, han venido a descubrir la importancia que para la economía tiene lo que sucede en los hogares y han puesto de manifiesto la fragilidad del equilibrio entre lo público y lo privado sobre el que descansa la economía capitalista, provocando la referida crisis de los cuidados que no es sino una crisis de estructura, de reordenación social de los trabajos y que tiene unas implicaciones de género centrales dado el reparto histórico de los trabajos de cuidado que ahora se plantea como consecuencia directa del envejecimiento de la población y las dificultades privadas de afrontar la dependencia ante la inexistencia de apoyo público. Se está ante la reestructuración del conjunto del sistema socioeconómico sin que se haya alterado por ello la división sexual del trabajo en los hogares ni la segmentación de género en el mercado laboral ${ }^{45} \mathrm{y}$, precisamente por ello, se concibe como un complejo "proceso de

${ }^{42}$ EZQUERRA, S.: "Crisis de los cuidados y crisis sistémica: la reproducción como pilar de la economía llamada real”, op. cit., p. 176.

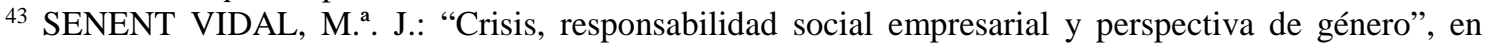
MESA MARRERO, C. (Dir.) y GRAU PINEDA, C. (Coord.): Mujeres, contratos y empresa desde la igualdad de género, Tirant lo Blanch, 2014, p. 571.

${ }^{44}$ EZQUERRA, S.: "Crisis de los cuidados y crisis sistémica: la reproducción como pilar de la economía llamada real”, op. cit., p. 177.

${ }^{45}$ La división sexual del trabajo ha generado un predominio del trabajo mercantil (productivo) sobre el trabajo doméstico y de cuidados (reproductivo) que ha fortalecido al primero en detrimento del segundo, absolutamente secundario respecto de aquel. Téngase en cuenta que, como se ha dicho, "en sociedades altamente monetarizadas como la nuestra, el valor por defecto es el dinero. Aquello por lo que no se percibe una remuneración, carece de valor, no vale. Si no invertimos esta escala de valores, difícilmente se reducirán las brechas entre mujeres y hombres”, en DIAZ, C., JABBAZ, M., AGUADO, E. Y GONZALEZ, L.: "Las brechas de género: brecha de cuidados y brecha salarial y brecha de tiempo propio”, op. cit., p. 35. 
desestabilización de un modelo previo de reparto de responsabilidades sobre los cuidados y la sostenibilidad de la vida, que conlleva una redistribución de las mismas y una reorganización de los trabajos de cuidados, proceso que está cerrándose actualmente de forma no solo insuficiente y precarizadora, sino reaccionaria, en la medida en que se basa en los mismos ejes de desigualdad social e invisibilidad de trabajos y agentes sociales que representa el modelo de partida ${ }^{46 ”}$.

\subsection{La traslación al debate jurídico-normativo}

Una y otra, crisis económica y crisis de cuidados, así como las sinergias existentes entre ambas, no hace sino poner de manifiesto el consenso actual sobre la necesidad de proporcionar un marco jurídico más adecuado para la protección de los derechos de las trabajadoras domésticas y conseguir un trabajo decente para ellas que llevó a la OIT a adoptar en 2011 el Convenio 189 y la Recomendación 201 sobre el trabajo decente para las trabajadoras y los trabajadores domésticos. Estos instrumentos sientan los principios básicos y las normas laborales mínimas para las trabajadoras domésticas a la vez que reconocen su naturaleza específica, así como la diversidad de los acuerdos laborales mediante los que se contrata a las trabajadoras domésticas en los distintos sistemas jurídicos y circunstancias socioeconómicas de los Estados Miembros. El Convenio 189 destaca, además, la importancia de tomar medidas que garanticen el cumplimiento de las leyes y reglamentos de protección de las trabajadoras domésticas, incluidos mecanismos sancionadores accesibles y la formulación y puesta en práctica de medidas relativas a la inspección de trabajo.

Si bien la legislación de numerosos países garantiza, incluso constitucionalmente, los mismos derechos a todos los trabajadores, ello no es óbice para que en estos países existan numerosas lagunas respecto al cumplimiento de la normativa. En algunos casos, la ley no contempla el sector adecuadamente o, donde lo hace, el trabajo doméstico no dispone de mecanismos como la inspección de trabajo, por ejemplo. En otros casos, la falta de recursos institucionales o de capacitación se añade a las características específicas del sector, a saber, la invisibilidad de la mano de obra y la inviolabilidad del domicilio privado, lo que dificulta la posibilidad de realizar inspecciones o poner en marcha cualquier otro mecanismo de control.

Brevemente, casi telegráficamente, interesa apuntar que se aplica el Convenio a todos los trabajadores domésticos, considerando como tal a "toda persona, de género femenino o género masculino, que realiza un trabajo doméstico en el marco de una relación de trabajo" y aclarando que trabajo doméstico es el "realizado en un hogar u hogares o para los mismos”, excluyendo la realización accidental o esporádica. Puede

\footnotetext{
46 PEREZ OROZCO, A.: “Amenaza tormenta: la crisis de los cuidados y la reorganización del sistema económico”, op. cit., pp. 9-10.
} 
abarcar una amplia gama de tareas que difieren de un país a otro, por ejemplo, cocinar, limpiar la casa, lavar y planchar, cuidado de los niños, de personas mayores y de enfermos, jardinería, chófer del coche familiar, cuidado de animales. El Convenio habilita a todo Miembro que lo ratifique para excluir total o parcialmente de su ámbito de aplicación -previa consulta con las organizaciones representativas de los empleadores y de los trabajadores- tanto a categorías de trabajadores para las cuales esté previsto otro tipo de protección que sea por lo menos equivalente como a las categorías limitadas de trabajadores respecto de la que se planteen problemas sustantivos especiales.

Ahora bien, las características específicas del sector del trabajo doméstico, y en concreto la naturaleza del lugar de trabajo, la relación de confianza entre el empleador y el trabajador, el uso y aceptación generalizado de acuerdos informales y la falta de información por ambas partes sobre la relación de trabajo, son factores que complican bastante la labor de promoción de la legislación laboral específica por parte de los gobiernos. Para la OIT, las respuestas equilibradas que prevean la prevención, la disuasión y la sanción resultan complicadas de obtener, por lo que se requiere de una legislación clara y concisa, el conocimiento de la legislación por parte de los empleadores, el reconocimiento de los derechos de las trabajadoras domésticas, medidas de fomento del cumplimiento de los requisitos legales, y un sistema que funcione respondiendo a las quejas, solucionando las diferencias y garantizando el respeto del estado de derecho. Pero, sobre todos estos aspectos, resulta de crucial importancia la aceptación social del valor del trabajo doméstico que no es otra cosa que la aceptación del valor del trabajo femenino. Ecuación en la que, repárese, el valor social que se otorgue al primero es directamente proporcional al reconocimiento del segundo porque es imposible considerarlos por separado, indisociablemente.

En definitiva, y para no dilatar por más tiempo el abordaje del Convenio 189, se trata de focalizar los debates pero, también, de verificar los avances en el impulso en favor de la igualdad real ${ }^{47}$. En los últimos años, el último quinquenio más concretamente, la labor de la OIT en este sentido ha sido encomiable. Ha lanzado las denominadas siete Iniciativas del Centenario, todas ellas enmarcadas en un conjunto de actividades organizadas y destinadas a preparar a la Organización para asumir los retos de su mandato en materia de justicia social en el futuro. Y, una de ellas, la Iniciativa del centenario de la OIT relativa a las mujeres en el trabajo: impulso en favor de la igualdad, tiene como objetivo fundamental tratar de comprender mejor y abordar los

\footnotetext{
${ }^{47}$ La dialéctica entre igualdad formal e igualdad sustancial, material o real caracteriza al Estado Social y en el caso de España, esta expresada en el art. $9 \mathrm{CE}$ al afirmar que corresponde a los poderes públicos "promover las condiciones para que la libertad y la igualdad del individuo y de los grupos en que se integra sean reales y efectivas; remover los obstáculos que impidan o dificulten su plenitud y facilitar la participación de todos los ciudadanos en la vida política, económica, cultural y social”. Sobre tal concepto, vid., in extenso, RAMOS QUINTANA, M.I.: "El principio de igualdad en las relaciones de trabajo: la no discriminación por razón de género”, en MESA MARRERO, C. (Dir.) y GRAU PINEDA, C. (Coord.): Mujeres, contratos y empresa desde la igualdad de género, Tirant lo Blanch, 2014, pp. 915 y ss.
} 
motivos por los cuales han sido tan lentos hasta ahora los progresos para hacer realidad el trabajo decente para las mujeres, al tiempo que pretende detectar qué es necesario hacer con el fin de garantizar un futuro mejor para las mujeres en el trabajo ${ }^{48}$.

\section{EL CONVENIO 189 DE LA OIT SOBRE TRABAJO DECENTE PARA LAS TRABAJADORAS Y LOS TRABAJADORES DOMESTICOS}

En junio de 2011 -pronto hará 8 años-, con ocasión de la 100ª reunión de la Conferencia Internacional del Trabajo de la Organización Internacional del Trabajo (OIT) se adoptó el Convenio 189 sobre trabajo decente para las trabajadoras y los trabajadores domésticos y su Recomendación correspondiente (la 201) que representan "la culminación de un movimiento mundial que aboga porque se mejore la protección de los derechos de los trabajadores domésticos ${ }^{49}$ ". Se trata de la primera vez que la OIT formula normas internacionales del trabajo destinadas a este grupo específico de trabajadores, mayoritariamente femenino, y entonces supuso un hito histórico en tanto en cuanto suponía una oportunidad para hacer del trabajo decente ${ }^{50}$ una realidad para las trabajadoras domésticas de todo el mundo ${ }^{51}$.

\subsection{La igualdad de género como nueva acción normativa preferente a nivel mundial}

Se considera que estos nuevos instrumentos "constituyen a la vez un sólido reconocimiento del valor económico y social que tiene el trabajo doméstico y un llamado a la acción para poner fin a las exclusiones de que son objeto las trabajadoras y los trabajadores domésticos en los ámbitos de la protección laboral y la protección

\footnotetext{
48 Más detalles en RAMOS QUINTANA, M.I.: "La iniciativa mundial relativa a las mujeres en el trabajo”, Revista Trabajo y Derecho, nº 51, 2019.

49 OELZ, M.: "El Convenio y la Recomendación de la OIT sobre las trabajadoras y los trabajadores domésticos. Una oportunidad para la justicia social”, op. cit., p. 190.

50 El Convenio 189 utiliza el concepto de trabajo decente que ha venido desarrollando la OIT desde finales del siglo XX y cuya génesis está en la Declaración de la OIT relativa a los principios y derechos fundamentales en el trabajo (1998) según la cual se declara que todos los Estados miembros, aunque no hayan ratificado los convenios reconocidos como fundamentales, tienen el compromiso, que se deriva de su mera pertenencia a la OIT, de respetar, promover y hacer realidad, de buena fe y de conformidad con la Constitución de la OIT, los principios relativos a los derechos fundamentales que son objeto de esos convenios. La culminación del concepto de trabajo decente se encuentra en la Declaración sobre la justicia social para una globalización equitativa (2008) al considerarlo como "el trabajo productivo para los hombres y las mujeres en condiciones de libertad, equidad, seguridad y dignidad humana. El trabajo decente supone que unos y otras tengan las oportunidades para realizar una actividad productiva que aporte un ingreso justo, seguridad en el lugar de trabajo y protección social para los trabajadores y sus familias; que ofrezca mejores perspectivas de desarrollo personal y favorezca la integración social; que de libertad a las personas para manifestar sus inquietudes, organizarse y participar en las decisiones que inciden en su vida; y que garantice la igualdad de oportunidades y de trato para todos”, en OIT: Guía práctica para la incorporación sistemática del empleo y el trabajo decente, Ginebra, 2008, p. vii.

51 Desde este momento todas las referencias al colectivo se harán en femenino plural por tratarse mayoritariamente de mujeres como se ha adelantado, decantándonos por la más contemporánea expresión de "empleadas o trabajadoras del hogar", mucho menos preñada de prejuicios y connotaciones negativas que la de "trabajadoras domésticas”.
} 
social. Dado que la mayoría de los trabajadores domésticos son mujeres, las nuevas normas son un paso importante hacia la realización de la igualdad de género en el mundo del trabajo y el ejercicio efectivo de la igualdad de derechos y de protección de

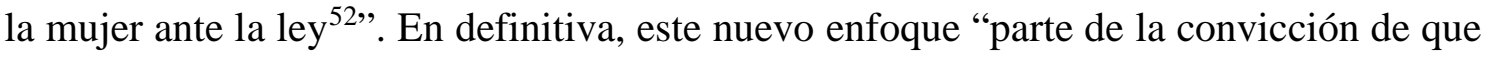
los empleados de hogar son trabajadores como los demás y, por tanto, pueden igualmente exigir que se respeten sus derechos y su dignidad ${ }^{53 \text { ”. }}$

Aunque ha tardado en ser realidad una norma internacional de este calado, finalmente y gracias a las presiones sindicales y de las organizaciones no gubernamentales e institucionales ${ }^{54}$, se ponen de relieve las prioridades de la OIT al respecto: el reconocimiento del trabajo decente para las empleadas de hogar ${ }^{55}$. Ambas normas internacionales "constituyen el marco internacional de normas y criterios dirigidos a construir el empleo del hogar como un «trabajo decente», dándole así valor social y económico, con el fin de contribuir a hacer efectivas las aspiraciones de las personas en su vida laboral, cuestión fundamental del concepto evolutivo de trabajo decente ${ }^{56}$,.

Según las estimaciones mundiales y regionales de la época ${ }^{57}$, al menos 52,6 millones de mujeres y hombres mayores de 15 años tenían su empleo principal en el trabajo doméstico, lo que representaba en torno al 3,6 \% de la fuerza de trabajo asalariada en todo el mundo. Las mujeres constituían la abrumadora mayoría de los trabajadores domésticos, el 83\% aproximadamente (43,6 millones) y suponía una fuente importante de empleo remunerado para las mujeres $(7,5 \%$ de la fuerza de trabajo femenina asalariada en todo el mundo). Los datos estadísticos mostraban entonces, igual que ahora, que el trabajo doméstico era un sector económico en plena expansión por lo que resultaba urgente que la OIT contribuyera a que ese desarrollo lo fuera en términos de justicia social e igualdad con la aprobación de normas como éstas.

Y es que hasta entonces, los organismos internacionales no habían conseguido sacar adelante ningún instrumento internacional obligatorio en defensa de las trabajadoras domésticas. Por ello, la doctrina científica española recibió su aprobación como "una

\footnotetext{
${ }^{52}$ OIT: Convenio núm. 189 \& Recomendación núm. 201 en pocas palabras, OIT, 2011, p. 2.

${ }^{53}$ OIT: Protección eficaz de los trabajadores domésticos: guía para diseñar leyes laborales, op. cit., p. 6.

${ }^{54}$ Es justo reconocer que tanto el Convenio 189 como la Recomendación 201 son el resultado de un amplio proceso preparatorio, fruto del consenso y que cuentan con un apoyo mayoritario.

${ }^{55}$ Es útil recordar que el "trabajo doméstico" definido en el contexto del Convenio núm. 189 se distingue del "trabajo a domicilio" o "trabajo en el hogar", que en el ámbito de las normas internacionales del trabajo está cubierto por el Convenio sobre el trabajo a domicilio, $1996\left(\mathrm{n}^{\circ} 177\right)$ que tampoco ha sido ratificado por España a la fecha de cierre de esta aportación. Se entiende por trabajo a domicilio el trabajo que una persona realiza en su propio domicilio, pero no en locales de trabajo del empleador.

${ }^{56}$ VELA DIAZ, R.: "La promoción internacional de un trabajo decente para las personas empleadas de hogar: el Convenio 189 de la OIT sobre trabajadores domésticos”, Revista del Ministerio de Empleo y Seguridad Social, $\mathrm{n}^{\circ}$ 127, 2017, p. 299.

${ }^{57}$ OIT: Convenio núm. 189 \& Recomendación núm. 201 en pocas palabras, op. cit., p. 6.
} 
conquista social ${ }^{58 \text { ” o "un punto de inflexión }}$ "59”, mediante el cual la OIT “integra a estos

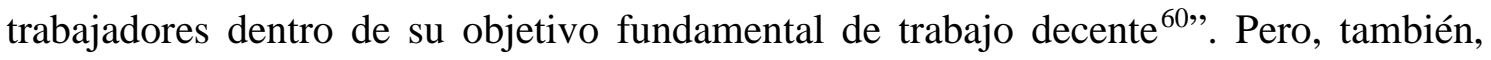
dentro del enfoque de derechos humanos que han asumido dichas normas jurídicas. El enfoque de derechos humanos ${ }^{61}$ resultaba del todo pertinente dado que hay muchos derechos que son a la vez humanos y laborales, cual género y especie, y "la mejora de unos repercute en la de los otros, de ahí que cada vez más se fomente la interacción entre ambos ${ }^{62 \text { ". }}$ El acervo sobre derechos humanos tiene una gran potencialidad para contribuir a la mejora de las condiciones de las empleadas de hogar y a la eliminación de muchas de las causas que explican su situación precaria y vulnerable. Es más, supone un importante paso en el objetivo final de consecución de la justicia social. Acertadamente se puso de relieve entonces "la honda trascendencia social y humana" de esta norma internacional que "trata de introducir en el ámbito del empleo formal (...) una actividad que, por su histórica marginación del ordenamiento del trabajo profesional, por sus connotaciones serviles y por carecer de valor productivo, ha sido considerada como una actividad “degradante” o cuanto menos de escasa relevancia, y por ello, objeto de actitudes que oscilaban entre el paternalismo de las posiciones cristianas, a la explotación típica y consecuente de las situaciones a que da lugar el trabajo invisible ${ }^{63}$ ".

Interesa focalizar ahora la atención en el hecho de que el concepto de trabajo decente aparece en la misma denominación del Convenio 189. Pero es que, en adición a lo anterior, llama poderosamente la atención la centralidad del trabajo decente en la construcción del Convenio 189 que desde las líneas preambulares afirma "el compromiso de la OIT de promover el trabajo decente para todos mediante el logro de las metas establecidas en la Declaración de la OIT relativa a los principios y derechos fundamentales en el trabajo y en la Declaración de la OIT sobre la justicia social para una globalización equitativa”. Es más, se parte del reconocimiento de que “el trabajo doméstico sigue siendo infravalorado e invisible” y el trabajo decente se presenta como solución a dicha infravaloración e invisibilidad.

Ya hemos tenido ocasión de adelantar que, pese a que el trabajo doméstico representa

\footnotetext{
58 QUESADA SEGURA, R.: "La dignificación del trabajo doméstico: el Convenio no 189 de la Organización Internacional del Trabajo, 2011”, Revista General de Derecho del Trabajo y de la Seguridad Social, $n^{\circ} 27,2011$, p. 1.

59 VELA DIAZ, R.: "La promoción internacional de un trabajo decente para las personas empleadas de hogar: el Convenio 189 de la OIT sobre trabajadores domésticos”, op. cit., p. 283.

${ }^{60}$ ROMERAL HERNANDEZ, J.: "El impacto del Convenio 189 de la OIT en las condiciones de trabajo de los empleados de hogar”, Revista doctrinal Aranzadi Social, n 7, 2013, p. 2.

${ }^{61}$ Este enfoque que acomete el Convenio 189 es novedoso en la actuación de la OIT porque, según el reparto clásico de competencias con la ONU, el ámbito de actuación de ésta son los derechos humanos y el de aquélla son los derechos laborales.

62 LOUSADA AROCHENA, J.F.: “Normativa internacional contra la explotación humana y laboral en el trabajo doméstico: la ONU y la OIT”, Lan Harremanak, nº 39, 2018, p. 174.

63 QUESADA SEGURA, R.: "La dignificación del trabajo doméstico: el Convenio no 189 de la Organización Internacional del Trabajo, 2011”, op. cit., p. 3.
} 
una parte significativa del empleo asalariado en el mundo, las trabajadoras del sector siguen, en su mayor parte, fuera del alcance de la legislación laboral y de Seguridad Social. Si por algo se caracteriza el sector, si hubiera que destacar un rasgo idiosincrásico por excelencia, sin duda alguna sería el de la amplia informalidad ${ }^{64}$ y/o formalidad precarizada exponencialmente; pero, también, el tratarse de un sector trufado de estereotipos que infravaloran la relevancia de este tipo de trabajo. Estereotipos entre los que el de género destaca sobremanera, no siendo el único, dado que está "cuantitativamente (...) feminizado, y cualitativamente es paradigma de la infravaloración de lo femenino ${ }^{65}$. Así es que la OIT, en línea con la ONU, ha calificado la igualdad de género -dentro de la política de trabajo decente- como una "nueva acción normativa preferente ${ }^{66 ”}$. El Convenio 189 deja meridianamente clara en su misma denominación la existencia de una perspectiva de género que impregna todo su contenido, como no podía ser de otro modo, pues habla de "las trabajadoras y los trabajadores domésticos” y reconoce que "el trabajo doméstico (...) lo realizan principalmente las mujeres y las niñas, muchas de las cuales son migrantes o forman parte de comunidades desfavorecidas, y son particularmente vulnerables a la discriminación con respecto a las condiciones de empleo y de trabajo, así como a otros abusos de los derechos humanos”. Aun hoy, las trabajadoras domésticas están expuestas a nivel mundial (y no solo en los países no desarrollados) a una gran variedad de abusos $^{67}$ en general, así como a transgresiones relacionadas con su derecho al pago de sus salarios, jornada laboral, condiciones de vida y falta de protección contra los accidentes laborales y enfermedades profesionales. La vulnerabilidad de las empleadas de hogar es aún mayor si cabe en el caso de las niñas, las migrantes y las minorías étnicas.

$\mathrm{Y}$, precisamente por ello, resultaba tan urgente, tan apremiante, el abordaje del déficit de trabajo decente característico del sector no solo mediante una legislación inclusiva, sino lo que es más importante si cabe, a través de su aplicación efectiva. Ha sido tan

\footnotetext{
${ }^{64}$ Las relaciones de trabajo informales de las trabajadoras domésticas son habituales en muchos países, tal y como lo reconocen los participantes de los dos foros regionales de la OIT para el intercambio de conocimientos, celebrados en Lisboa (Portugal) del 11 al 12 de octubre de 2012 y en Dar es Salaam (República Unida de Tanzania) del 28 al 30 de mayo de 2012. En este último, algunos participantes relataron que en la mayoría de los países africanos la seguridad social para los trabajadores domésticos era algo nuevo que no era aceptado por los empleadores. La relación de trabajo de carácter informal afecta también a otras regiones; por ejemplo, la Fundación Europea para la Mejora de las Condiciones de Vida y de Trabajo (Eurofound) estimó que, en la Unión Europea, la incidencia del trabajo no declarado en los hogares familiares era del $19 \%$ en 2008. Solo señalar aquí y ahora que el sector informal de la economía es "una consecuencia de los efectos de una globalización sin controles. Este modelo económico ha generado una reducción ciertamente limitada de la inseguridad y la vulnerabilidad en los mercados de trabajo. Dicha situación ha afectado muy especialmente a los mercados de trabajo de las economías en desarrollo", en LOPEZ AHUMADA, E.: "Trabajo informal, transición a la formalidad e inclusión social en Latinoamérica”, op. cit., p. 12.

${ }^{65}$ LOUSADA AROCHENA, J.F.: "Normativa internacional contra la explotación humana y laboral en el trabajo doméstico: la ONU y la OIT”, op. cit., p. 169.

${ }^{66}$ OIT: Memoria sobre el trabajo decente, 1999.

${ }^{67}$ Incluidos la violación de derechos humanos, la libertad de movimiento y el respeto de la vida privada.
} 
crucial el reconocimiento de la necesidad de hacer del trabajo decente una realidad para las trabajadoras domésticas gracias a la aprobación del Convenio $189^{68}$ que proporciona, nada más y nada menos, un marco normativo para estas acciones y que, ya podemos decirlo, ha empezado a repercutir en la reforma de la legislación social en favor del reconocimiento de este trabajo como trabajo decente. De ahí que haya quienes apuntan que estos instrumentos normativos mundiales deben de funcionar como “catalizadores del cambio ${ }^{69}$ ”. La campaña mundial para la adopción de estos instrumentos se ha transformado en un movimiento que aboga por su ratificación y aplicación y que está dando un nuevo impulso a la organización colectiva de las trabajadoras domésticas. Pese a que las particulares características del sector del trabajo doméstico hacen que el enfoque normativo y de cumplimiento resulte complicado, es “imprescindible para dignificar el trabajo doméstico y para promover la erradicación de los prejuicios que se encuentran en los cimientos de la servidumbre doméstica ${ }^{70}$ ". Y es que conviene tener presente que "el ámbito del trabajo doméstico es uno de en ellos que más frecuentemente se producen situaciones de servidumbre doméstica o esclavitud laboral, según se ha denunciado reiteradamente desde diversos organismos internacionales ${ }^{71}$ ".

Por todo ello, no se puede cuestionar ni la importancia ni la oportunidad que supone para la construcción por parte de los países de un régimen protector de derechos sociales a favor de este grupo de personas que prestan sus servicios en el ámbito doméstico, favoreciendo así que emerjan de la invisibilidad que las caracteriza y dignificando este sector laboral. La ratificación del Convenio 189, además de ser una cuestión de justicia social, es importante también en términos económicos y de seguridad social. Es

68 El Convenio sobre el trabajo decente de las trabajadoras y los trabajadores domésticos, 2011 (núm. 189), entró en vigor el 5 de septiembre de 2013. Hasta el momento ha sido ratificado por 27 Estados entre los que no está España: Argentina, Bélgica, Bolivia, Brasil, Chile, Colombia, Costa Rica, República dominicana, Ecuador, Finlandia, Alemania, Guinea, Guyana, Irlanda, Italia, Jamaica, Mauricio, Nicaragua, Panamá, Paraguay, Filipinas, Portugal, Sudáfrica, Suiza y Uruguay. Granada y Perú lo han ratificado pero su fecha prevista de entrada en vigor está prevista para el 12 y el 26 de noviembre de 2019, respectivamente.

${ }^{69}$ OELZ, M.: "El Convenio y la Recomendación de la OIT sobre las trabajadoras y los trabajadores domésticos. Una oportunidad para la justicia social”, op. cit., p. 190.

${ }^{70}$ LOUSADA AROCHENA, J.F.: "Normativa internacional contra la explotación humana y laboral en el trabajo doméstico: la ONU y la OIT”, op. cit., p. 182. A mayor ahondamiento sobre la servidumbre doméstico, vid. LERUSSI, R. "Servidumbres doméstica en contextos latinoamericanos: aproximaciones socio-jurídicas”, en PEREZ ALONSO, P. (Dir.): El derecho ante las formas contemporáneas de esclavitud, Tirant lo Blanch, 2017, p. 757 y ss. En donde se dice que "lo que pervive a modo de legados coloniales en las modalidades de servidumbre doméstica actuales, puede no estar presente en la letra de la ley pero si estarlo en sus tramas interpretativas (jurídicas, por ejemplo), en los usos y en las prácticas socio-laborales así como en los supuestos epistémicos que conectan al empleo doméstico y de cuidados con las antiguas servidumbres”, p. 771.

${ }^{71}$ MIÑARRO YANINI, M.: "Formas esclavas de trabajo y servicio del hogar familiar: delimitación conceptual, problemática específica y propuestas”, Relaciones Laborales, $\mathrm{n}^{0}$ 10, 2014, p. 71. LA autora considera que se trata de "un campo abonada para comportamientos abusivos, porque se conjugan una serie de elementos que inciden en ello, como son, entre otros, el desarrollo del trabajo en un ámbito privad muy cerrado y poco visible, la concurrencia de factores de vulnerabilidad de las víctimas y la práctica ausencia de controles sociales y del Estado”, p. 72. 
importante que se ratifiquen esos instrumentos y que se promulguen nuevas leyes a escala nacional para nivelar la protección otorgada a las trabajadoras domésticas con la que disfrutan los demás trabajadores y se establezcan derechos legales que les amparen, pero los avances en el ámbito jurídico no bastarán para lograr una mejora de las condiciones en la práctica.

En este sentido, se ha apuntado con gran acierto que "a tal fin, se necesita un conjunto de estrategias a más largo plazo. Son muchos los países que han de incluir a los trabajadores domésticos en sus estadísticas nacionales sobre empleo y condiciones de trabajo, con el fin de facilitar las actividades de sensibilización y la formulación y evaluación de políticas basadas en datos empíricos. Dado que el trabajo doméstico constituye todavía un ámbito de intervención nuevo o emergente para muchísimos Estados, es importante que en los próximos años los países y las regiones intercambien sus resultados y experiencias ${ }^{72}$ ”. Pero, también será necesario invertir esfuerzos para hacer entender que el trabajo doméstico implica una relación de trabajo, y que se precisan medidas concretas e incentivos para promover la formalización. Y, aunque sin duda alguna se trata de una ardua tarea, propiciar y conseguir un cambio drástico en las condiciones de trabajo y de protección social que afectan a las trabajadoras del ámbito doméstico, en la línea marcada tanto por el Convenio 189 como por su Recomendación 201 que, in fine, son las que articulan el paradigma para tratar de consolidar esta transformación.

\subsection{Los diversos enfoques nacionales sobre la regulación del trabajo doméstico}

Ya se ha tenido ocasión de analizar cómo el Convenio 189 promueve una regulación estatal que garantice a las empleadas de hogar "las condiciones mínimas de trabajo y de seguridad social equiparables al resto de los trabajadores, así como el establecimiento de un sistema de protección judicial y de tutela administrativa que lo haga posible, entrando, incluso, en una regulación minuciosa de determinados derechos (...) si bien, ignora otros aspectos de esta relación de trabajo o, sencillamente, remite a la regulación de los Estados miembros aquellos otros en los que resulta más conflictiva una regulación generalizada ${ }^{73}$ ”.

Desde el ámbito mundial que representa la OIT, se apela a la intervención estatal, vía ratificación de sus convenios y recomendaciones, para asegurar la igualdad de género vía la dignificación del trabajo doméstico y de cuidados. Ahora bien, los enfoques nacionales sobre la regulación del trabajo doméstico son muy variados y dependen de la legislación laboral de cada país. En algunas jurisdicciones, el trabajo doméstico está regulado en varios capítulos, títulos o disposiciones especiales de los códigos de trabajo

\footnotetext{
72 OELZ, M.: "El Convenio y la Recomendación de la OIT sobre las trabajadoras y los trabajadores domésticos. Una oportunidad para la justicia social”, op. cit., p. 192.

73 QUESADA SEGURA, R.: "La dignificación del trabajo doméstico: el Convenio no 189 de la Organización Internacional del Trabajo, 2011”, op. cit., p. 4.
} 
o legislación sobre el empleo (p.e. Bélgica), mientras que en otros este tipo de trabajo cuenta con una legislación específica (p.e. España y Portugal). Los convenios colectivos forman parte también del marco normativo nacional para el trabajo doméstico en algunos países (Francia ${ }^{74}$ e Italia ${ }^{75}$ ).

Desde la adopción del Convenio 189, un creciente número de países, han iniciado o culminado sus reformas legales con el objeto de mejorar el reconocimiento de sus derechos, pero a pesar de la tendencia positiva hacia la ampliación de las disposiciones de la legislación laboral para incluir a las trabajadoras domésticas en pie de igualdad con los demás trabajadores, en muchos países se les continúa privando de sus derechos del trabajo y su condición no les confiere la misma protección ni laboral ni social. En algunos países el trabajo doméstico está todavía totalmente excluido de la legislación laboral (Egipto e Indonesia), mientras que en otros la legislación del trabajo no aborda el tema, lo que conduce a problemas de interpretación.

En las páginas siguientes pretende centrarse la atención en nuestro país. Y es que pese a que España es el país europeo con mayor número de empleadas del hogar (28.6\% del total del empleo del sector en toda Europa), seguida muy de cerca por Francia e Italia, sigue sin ratificar dicho Convenio, lo que no es óbice para que cuente con regulación nacional específica al respecto. Pero veámoslo detenidamente.

\section{REGULACIÓN ESPAÑOLA DEL TRABAJO DOMÉSTICO: EL “MISTERIO” DE LA NO RATIFICACIÓN DEL CONVENIO 189}

La regulación española del trabajo doméstico se debate entre la aceptación pacífica y sosegada de unos aspectos y la inacción político-legislativa frente a otros que resultan más conflictivos por razones diversas. Sin ánimo de hacer una exposición detallada de unos y otros, lo que queda fuera del objeto de estudio, sí que quieren destacarse algunos hitos que reflejen las posibles razones de la falta de ratificación del Convenio 189 OIT.

Recién aprobado el Convenio 189, era generalizado no dudar ni “de la oportunidad de la norma y de su necesidad y justicia, (...) [ni] del éxito de su ratificación, salvo en aquellos Estados en donde, por gozar de Constituciones sociales y de un sistema de bienestar social, hace tiempo que se les ha considerado como trabajadores por cuenta ajena si bien, en la mayoría de los casos, con una regulación específica basada en las peculiaridades de este tipo de trabajo ${ }^{76}$ ". Sin embargo, ocho años después, seguimos sin la ansiada ratificación y lo cierto es que nos extraña a todos. Es difícil entender como un Estado Social y Democrático de Derecho como España ha optado por quedarse de

${ }^{74}$ La Convention Collective Nationale des salaries du particulier employeur du 24 novembre 1999, disponible en www.legifrance.guv.fr

75 Contratto Colletivo Nazionale del Lavoro Domestico, disponible en www.assindatcolf.it/informazionitecniche/contratto-nazionale-del-lavoro

76 QUESADA SEGURA, R.: "La dignificación del trabajo doméstico: el Convenio no 189 de la Organización Internacional del Trabajo, 2011”, op. cit., p. 5. 
brazos cruzados y mantenerse al margen de este movimiento mundial. Y precisamente por ello las principales críticas que desde la doctrina se arrojan van en la línea de lo crucial que resulta en estos momentos "contar con la existencia de una clara voluntad por hacer cumplir y vigilar el cumplimiento de estas normas nuevas que pueden parecer mínimas y superadas ampliamente hoy en día, representando un cambio sustancial en las condiciones de empleo de un amplio sector del trabajo doméstico ${ }^{77}$ ”.

\subsection{Las posibles razones (I): entre la tradición y la etnización}

Hay quienes encuentran las razones en nuestra historia reciente. Y es que, para los historiadores del Derecho “a través del análisis histórico-jurídico de la normativa social de los diversos periodos de la Dictadura franquista, observamos como el servicio doméstico es el gran marginado de todas las ampliaciones de derechos sociales que lentamente se practicaron ${ }^{78}$ ”. A mayor abundamiento, “el franquismo negó a la mujer su desarrollo personal y profesional postergándola al hogar (...). De este modo, vemos como la empleada del hogar es una suerte de "miembro putativo" de la familia, una extensión de la misma, motivo por el cual el Estado debe ceder ante la potestad del cabeza de familia (...). Podemos afirmar que el servicio doméstico durante el franquismo concentró sobre la mujer la marginación, la represión y la discriminación de cuarenta largos años de Dictadura ${ }^{79}$ ". Y es que cuesta, temporalmente hablando, superar concepciones tan arraigadas en nuestro ADN como ésta. Es obvio que superar 40 años ya no de retraso, sino de regresión política y social, por mucho que estemos demostrando ganas de superar y dejar atrás, lleva su proceso. Pero llama poderosamente la atención que países de nuestro entorno constitucional hayan culminado positivamente ese mismo proceso y, sin embargo, España lo haya iniciado pero muy tímidamente.

Pero soy de las que opinan que hay otra razón principal: la etnización de este sector. Tercer factor de discriminación que, junto a la feminización y la segregación ocupacional, consolidan la vulnerabilidad característica de las trabajadoras de este sector $^{80}$. Los datos son sesudos y demuestran que en aquellos países en los que la brecha entre ricos y pobres es considerable, la demanda de mano de obra suele satisfacerse internamente, a menudo recurriendo a migrantes nacionales procedentes de zonas rurales. A escala mundial, sin embargo, los trabajadores domésticos son, muy a

\footnotetext{
77 SANZ SAEZ, C.: "La discriminación en contra de las empleadas de hogar como forma de manifestación de las discriminaciones múltiples”, op. cit., pp. 106-107.

${ }^{78}$ CAÑABATE PEREZ, J.: ““'Servir es distinto a trabajar”: Potestad del cabeza de familia vs. Protección social del servicio doméstico en la dictadura franquista”, en GARCIA GONZALEZ, G. Y ESPUGNY I TOMAS, M. ${ }^{a}$. J. (coord.): Relaciones laborales y empleados del hogar: reflexiones jurídicas, Dykinson, 2014, p. 61.

${ }^{79}$ CAÑABATE PEREZ, J.: ““'Servir es distinto a trabajar”: Potestad del cabeza de familia vs. Protección social del servicio doméstico en la dictadura franquista”, op. cit., p. 80.

${ }^{80}$ Más detalles sobre la discriminación múltiple característica de este colectivo en SANZ SAEZ, C.: "La discriminación en contra de las empleadas de hogar como forma de manifestación de las discriminaciones múltiples”, op. cit, pp. 89-108.
} 
menudo, migrantes internacionales. Si bien hace cuarenta años la migración para trabajar en el servicio doméstico era un fenómeno aislado, hoy se cree que las trabajadoras domésticas representan un porcentaje importante de la mano de obra migrante en todo el mundo. La demanda de trabajadoras domésticas es uno de los factores clave que explican la feminización de la migración, tanto Sur-Norte como Norte-Norte o en otras rutas migratorias mundiales, y recientemente los discursos diplomáticos sobre migración han reconocido como un objetivo compartido mejorar la protección de las trabajadoras domésticas migrantes ${ }^{81}$. Y, aunque un número relativo de hombres trabaja en el sector - con frecuencia como jardineros, chóferes o mayordomos -, sigue siendo un sector donde predominan las mujeres: $80 \%$ de todas las trabajadoras domésticas son mujeres. En España, la última EPA muestra que 637.700 personas (96\% mujeres y 42\% mujeres extranjeras) están ocupadas en este sector.

La contratación de las mujeres inmigrantes posibilita, en España y en los países desarrollados, la conciliación de la vida laboral y familiar de las mujeres ${ }^{82}$ nativas que, sin apoyos públicos, resuelven sus dificultades laborales recurriendo, de forma privada, a las primeras y provocando con ello un "trasvase de desigualdades de mujeres", dando lugar a la construcción de mujeres "servidas" y mujeres "servidoras" 83 . Para muchas mujeres inmigrantes, trabajar en el servicio doméstico se convierte en la única opción laboral que tienen al llegar y esto está estrechamente relacionado no solo con la normativa laboral sino, además, con la de inmigración y extranjería. Y es que, "la capacidad para contratar al amparo de este tipo de relaciones especiales a quienes no ostentan la nacionalidad española se halla condicionada (...) por la compleja normativa sobre extranjería. (...) Es preciso tener en cuenta que se trata de un sector de la economía en el que la presencia de trabajadores extranjeros es absolutamente mayoritaria, por no decir casi exclusiva. (...) Esta posición "subalterna” se ha visto reforzada por el hecho de que el trabajo doméstico se ha convertido en una de las principales vías de incorporación de la mujer extranjera al mercado de trabajo ${ }^{84 ”}$.

${ }^{81}$ OELZ, M.: "El Convenio y la Recomendación de la OIT sobre las trabajadoras y los trabajadores domésticos. Una oportunidad para la justicia social”, op. cit., p. 163.

${ }^{82}$ En este sentido se ha apuntado que "en el fomento de la corresponsabilidad en el ámbito de la conciliación, sigue siendo necesario promover un cambio social profundo (...) [que tome en consideración] cuatro elementos fundamentales: la neutralidad en el género de los cuidadores del hogar, un reparto equilibrado de las responsabilidades doméstica y de cuidad, la toma en consideración de nuevas estructuras de familia (...) y la ampliación del marco de corresponsabilidad no solo al cuidado de los menores sino también a la atención de otros familiares”, en RODRIGUEZ GONZALEZ, S.: "Igualdad, trabajo y responsabilidades familiares. Un enfoque desde las políticas autonómicas de conciliación de la vida familiar y laboral”, en MESA MARRERO, C. (Dir.) y GRAU PINEDA, C. (Coord.): Mujeres, contratos y empresa desde la igualdad de género, Tirant lo Blanch, 2014, p. 964.

${ }^{83}$ PARELLA RUBIO, S.: "El trasvase de desigualdades de clase y etnia entre mujeres: los servicios de proximidad”, Papers, $\mathrm{n}^{0}$ 60, 2000, pp. 275-289. De la misma autora, vid. Mujer, inmigrante y trabajadora: la triple discriminación, Anthropos, Rubí, 2003.

${ }^{84}$ GRAU PINEDA, C. y DOMINGUEZ-MUJICA, J.: "La persistencia de mujeres inmigradas en el servicio doméstico en España en tiempos de recesión económica: datos para la reflexión”, Revista de derecho migratorio y extranjería, no 40, 2015, p. 84. 
En otras palabras, lo que se ha dado en denominar la "cadena transnacional del cuidado", es la que "ha garantizado durante años la pervivencia del capitalismo patriarcal a la vez que ha invisibilizado su naturaleza excluyente. La crisis de los cuidados no ha sido resuelta, de esta manera, mediante una generalizada y equitativa implicación de los hombres en el trabajo del cuidado, ni un fortalecimiento de las responsabilidades reproductivas del estado ni, por descontado, una feministización del mercado laboral ${ }^{85}$ ". La presencia de mujeres inmigrantes consolida, por tanto, la “feminización” del sector en ambos lados de la relación laboral. Es decir, "aunque parte de las actividades domésticas se han mercantilizado, continúan siendo "cosas de mujeres" tanto por quién las realiza como por quién las contrata y gestiona su trabajo. El trabajo reproductivo sigue atribuyéndose a las mujeres, sin cuestionar las relaciones patriarcales en la sociedad que apenas cambian en el ámbito privado dado que los varones no se implican ni en la realización ni en la gestión de este trabajo ${ }^{86 ” . ~ E n ~}$ definitiva, un deslizamiento de la división sexual del trabajo que descansa sobre la explotación laboral de las sustitutas o servidoras, que decíamos antes, y perpetúa la discriminación en un mercado laboral profundamente segmentado. Como se ha puesto de manifiesto "las contradicciones visibilizadas por la crisis de los cuidados han sido así gestionadas hasta hace bien poco mediante una externalización e internacionalización de la solución, las cuales, además de eximir al estado, al mercado y a los hombres de gran parte de su responsabilidad reproductiva, han dado entrada a nuevos ejes de desigualdad y han acentuado los previamente existentes ${ }^{87}$,"

En la línea de garantizar una migración con seguridad jurídica ${ }^{88}$, el Convenio 189 OIT añade en su art. 8.3 que los Miembros deberán adoptar medidas para cooperar entre sí a fin de asegurar la aplicación efectiva de las disposiciones del presente Convenio a los trabajadores domésticos migrantes. También se establece en el art. 8.4 del Convenio que todo Miembro deberá especificar, mediante la legislación u otras medidas, las condiciones según las cuales los trabajadores domésticos migrantes tienen derecho a la repatriación tras la expiración o terminación del contrato de trabajo en virtud del cual fueron empleados - una repatriación que la Recomendación aconseja se realice sin costo para el trabajador ex disposición 22-. La otra referencia a los trabajadores migrantes contenida en el articulado del Convenio es para aclarar que se les aplicarán las medidas

\footnotetext{
${ }^{85}$ EZQUERRA, S.: “Crisis de los cuidados y crisis sistémica: la reproducción como pilar de la economía llamada real”, op. cit., p. 190.

${ }^{86}$ PLA JULIAN, I.: Informalidad del empleo y precariedad laboral de las empleadas de hogar (20032004), Estudios e Investigaciones del Instituto de la Mujer, Ministerio de Igualdad, 2004, p. 57. Recurso electrónico disponible http://www.inmujer.gob.es/publicacioneselectronicas/documentacion/Documentos/DE0097.pdf

${ }^{87}$ EZQUERRA, S.: “Crisis de los cuidados y crisis sistémica: la reproducción como pilar de la economía llamada real”, op. cit., p. 190.

88 SANZ SAEZ, C.: "Derechos colectivos y empleadas del hogar: reformas jurídicas inaplazables para un trabajo decente del trabajo doméstico en España”, comunicación presentada y seleccionada respecto de la conversación II “Trabajo decente para todos” en el Congreso Interuniversitario OIT sobre el futuro del trabajo, Sevilla, 7-8 febrero 2019, p. 16 ejemplar multicopiado y proporcionado por la autora.
} 
previstas para los trabajadores domésticos contratados o colocados por agencias de empleo privadas, cuando estén en esas situaciones ${ }^{89}$ (art. 15). Además, la Recomendación 201 OIT, aconseja a los Estados de origen contribuir a la protección efectiva de los derechos de estos trabajadores, informándoles acerca de sus derechos antes de que salgan de su país, creando fondos de asistencia jurídica, servicios sociales y servicios consulares especializados y adoptando toda medida que sea apropiada (disposición 21). Y España, de ratificarlo, deberá revisar muchos de estos ítems a la luz de su política migratoria y su marco normativo específico.

\subsection{Las posibles razones (II): entre reticencias superables y resistencias infranqueables}

No resulta en modo alguno baladí recordar que en España se produjo una mejora legislativa a finales del año 2011 cuando se aprobó el RD 1620/201190, de 14 de noviembre, que proporcionó un nuevo marco normativo para este tipo de prestación de servicios -sustituyendo a su antecedente temporal inmediato el RD 1424/1985 ${ }^{9}$-, con el objetivo de establecer "mayores y mejores derechos de los trabajadores, aplicando, en lo que resulte factible, la regulación general contemplada en el Estatuto de los Trabajadores y normativa complementaria” (Preámbulo RD 1620/2011).

Téngase en cuenta que el RD 1620/2011 se encuadra en el proceso de aproximación de la regulación del servicio del hogar familiar a la normativa común, iniciado por la integración en el Régimen General de la Seguridad Social del Régimen Especial de

\footnotetext{
${ }^{89}$ En la misma línea aclaratoria, hay varias referencias en la Recomendación en relación con la seguridad social (disposición 20), con la protección efectiva (disposición 22) o de nuevo con las agencias privadas de colocación (disposición 23).

90 Además de la Ley 27/2011, de 1 de agosto, sobre actualización, adecuación y modernización del sistema de Seguridad Social, modificada parcialmente por el RDL 29/2012, de 28 de diciembre, de meja de la gestión y la protección social en el sistema especial para empleados de hogar y otras medidas de carácter económico y social. Con estas normas se incluye a las empleadas de hogar en el RGSS, concretamente en un sistema especial (SEEH), con el objetivo confesado de la equiparación gradual de las condiciones de trabajo de este ámbito con el resto de sectores incluidos en el RGSS. Por su parte, el Real Decreto-ley 29/2012, de 28 de diciembre, de mejora de gestión y protección social en el Sistema Especial para Empleados de Hogar y otras medidas de carácter económico y social, intento, al menos en la teoría, establecer un periodo transitorio de equiparación progresiva de estas trabajadoras al RGSS, estableciendo un plazo de adaptación que venció el pasado 31 de diciembre de 2018 sin resultados (calendario de equiparación gradual 2012-2018). Con todo, es preciso tener en cuenta que, "no se efectúa la plena equiparación en ninguno de dichos ámbitos. (...) Por consiguiente, en sendas vertientes persisten elementos diferenciadores respecto del modelo considerado general”, en MIÑARRO YANINI, M.: El trabajo al servicio del hogar familiar: análisis de su nueva regulación, Reus, 2013, p. 10.

${ }^{91}$ Parece evidente que las casi tres décadas que habían transcurrido desde la aprobación del Real Decreto 1424/1985 aconsejaban modernizar una regulación que en ciertos aspectos se encontraba obsoleta, pues la fisonomía del trabajo doméstico presenta hoy unos perfiles diferentes, con preponderancia del trabajo a tiempo parcial sobre el trabajo a tiempo completo, y en un contexto donde en muchas ocasiones el poder negociador del empleado de hogar es elevado, pues la demanda de esta clase de actividad es alta, y los ingresos que obtiene el trabajador son complementarios dentro de la unidad familiar, y de ordinario no constituyen una parte tan sustancial que derive en una compulsión económica de tal intensidad que conduzca a la aceptación de condiciones impuestas unilateralmente.
} 
Empleados de Hogar (con peculiaridades), efectuada por la Ley 27/2011, sobre actualización, adecuación y modernización del sistema de Seguridad Social que anunciaba, en su DA 39ª .5, la modificación de la relación laboral especial del servicio del hogar familiar con efectos de 1 de enero de 2012. Es por ello que, como acertadamente se ha dicho, "aquella norma supone una considerable mejora respecto de la disposición precedente, en lógica con la tendencia de laboralización-normalización sustancial del trabajo doméstico en la que se encuadra, puesto que mitiga el signo ciertamente civilista que estaba presente en la norma de 1985 (...) el RD de 2011 ha corregido o matizado muchos de los “puntos oscuros” incluidos en el RD 1424/1985 que desequilibraban, aún más, la relación entre el empleador y el empleado del servicio doméstico ${ }^{92 \%}$.

El legislador pretendía entonces "hacer aflorar una actividad que en buena medida se encontraba extra muros de la legislación laboral y de Seguridad Social, y que por tanto no daba lugar a los pertinentes ingresos a través del cumplimiento de las obligaciones tributarias y de cotización ${ }^{93}$ ”. “Aflorar” como sinónimo de promover la transición de la informalidad a la economía formal y al trabajo declarado, de promocionar la inclusión social, la equidad social y, en definitiva, la justicia social. En este sentido, parece un objetivo demasiado excelso para un $\mathrm{RD}$ tan modesto como éste cuya principal virtud no va más allá de aproximar esta relación laboral especial a la relación laboral común. No obstante, las modificaciones más relevantes, por haber implicado cambios notables de procedimiento e, incluso, de “comportamiento social ${ }^{94 ”, ~ s e ~ h a n ~ p r o d u c i d o ~ e n ~ e l ~ a ́ m b i t o ~}$ de la Seguridad Social al convertir al titular del hogar familiar en un verdadero empleador que ha de cumplir exigencias de las que antes estaba exento.

En cualquier caso, conviene tener muy presentes dos de los principales escollos que la aplicación de la normativa encuentra. $\mathrm{Y}$ es que, en primer lugar, se trata de una actividad que en buena medida se desenvuelve al margen del control y vigilancia de las Administraciones Públicas, dentro de la economía informal o sumergida, especialmente cuando se desarrolla a tiempo parcial porque la retribución es reducida y la merma que provocaría el cumplimiento de las obligaciones fiscales y de Seguridad Social, desincentiva el "afloramiento". Y, en segundo lugar, consecuencia de lo anterior, las dificultades de control favorecen ese tipo de acuerdos entre las partes para eludir las

\footnotetext{
${ }^{92}$ MIÑARRO YANINI, M.: El trabajo al servicio del hogar familiar: análisis de su nueva regulación, op. cit., pp. 19-20.

${ }^{93}$ RODRIGUEZ CARDO, I. A.: "La relación laboral especial de los empleados de hogar", Revista del Ministerio de Empleo y Seguridad Social, $n^{\circ}$ 118, 2015, p. 50.

${ }^{94}$ Ídem. En esta misma línea, se apunta que "es importante promover campañas de información desde el Ministerio de Empleo y Seguridad Social que logren alterar a percepción popular de que el trabajo doméstico es de segunda categoría, a fin de sensibilizar a la población sobre su importancia y lograr así impulsar el cumplimiento de las normas que lo regulan", en MIÑARRO YANINI, M.: "Formas esclavas de trabajo y servicio del hogar familiar: delimitación conceptual, problemática específica y propuestas”, op. cit., p. 85.
} 
obligaciones tributarias y de cotización. Cierto es que la legislación laboral contribuye notablemente a que las empleadas de hogar pasen de trabajar en la economía informal a tener una relación de trabajo formalizada, pero también lo es que, dificultades como las apuntadas y otras como la complejidad de los trámites de gestión de la contratación en este sector, dificultan dicho tránsito ${ }^{95}$.

Todo ello nos lleva a preguntarnos si en el origen de la falta de ratificación del Convenio 189 OIT lo que hay son meras reticencias o resistencias de mayor consideración. Me explico: si consideramos como sinónimo de reticencias, los términos “desconfianza” o “cautela” que algo inspira; y de resistencias, los términos “oposición” o "protesta” frente a un cambio; resulta que es posible constatar ambas en el núcleo medular de dicha falta de ratificación. Veámoslo.

Y es que, si como se ha adelantado, la situación por países dista considerablemente de ser homologable y, según el contexto mundial en el que se ubiquen, hay países que consideran que el texto del Convenio (y su Recomendación) es demasiado preceptivo; mientras que para otros, es la legislación nacional vigente -que debe estar acorde con las disposiciones de la OIT- la que plantea numerosos obstáculos a su ratificación en tanto en cuanto no se proceda a la adaptación interna previa. En el caso concreto de España, ubicado entre los segundos, es por todos conocido que hay aspectos del trabajo doméstico -los más- que si bien inicialmente planteaban problemas y desajustes respecto de la normativa internacional (y nacional), ya están superados, al menos de iure, como ocurre con el trabajo forzoso o infantil, contratación, la regulación de la jornada y los descansos, el pago salario y los límites al salario en especie, etc. Se trata de hitos a superar por regulaciones más propias de países en desarrollo, lo que no quiere decir que haya que bajar la guardia dada la vulnerabilidad característica del sector en cuestión. Ahora bien, dicho esto, hay otros aspectos de este sector que están lastrando, impidiendo dicha ratificación por España, principalmente por la falta de adaptación de la normativa interna a los contenidos del convenio y en los que me gustaría incidir en las líneas que siguen agrupados en función de que visibilicen una reticencia (a.) o una resistencia (b.).

\section{a. De las reticencias superables}

En cuanto a las reticencias, superables a base de trabajar las desconfianzas o reparos constatados al respecto, pueden situarse tanto la peculiaridad del desistimiento por el empleador como las dificultades para que la Inspección de Trabajo y de la Seguridad Social (ITSS) pueda velar por el cumplimiento de la normativa laboral vigente.

Respecto de la primera, la confianza inherente en este sector se presenta como la justificación de la que trae causa esta forma específica de extinción, el desistimiento, que no se contempla en la relación laboral común (salvo durante el periodo de prueba). El empleador en este supuesto, puede instar la extinción del contrato en cualquier momento durante su vigencia, amparándose en la pérdida de confianza, y no siendo necesaria la alegación de una causa concreta, y dando lugar a una indemnización reducida ${ }^{96}$. No deja de sorprender dado que son variados los ejemplos en los que la "especial confianza” cualifica el vínculo contractual (alta dirección, por ejemplo) y, sin embargo, en este caso se permite,

\footnotetext{
95 Informe Anual del Defensor del Pueblo de año 2012.

96 Simultáneamente a la comunicación de la extinción, el empleador deberá poner a disposición del trabajador una indemnización, que se abonará íntegramente en metálico, en cuantía equivalente al salario correspondiente a doce días naturales por año de servicio, con el límite de seis mensualidades (art. 11.3 RD 2011).
} 
pensamos, que por el coste económico que la indemnización por despido puede suponer para la “economía familiar”. Conviene tener presente que la DA 2a RD 1620/2011 contemplaba la constitución de un grupo de expertos para la elaboración de un informe que valorase la "viabilidad de aplicar plenamente el régimen de extinción del contrato de trabajo de la relación laboral común establecido en el Estatuto de los Trabajadores a la relación laboral de carácter especial del servicio del hogar familiar, así como la posibilidad de incluir el desistimiento del empleador, entendido como pérdida de confianza en el empleado, en alguna de las causas comunes de extinción del contrato de trabajo establecidas en el artículo 49 del Estatuto de los Trabajadores”. Hecho que no se ha producido ni está previsto que se produzca cuando resulta de todo conveniente "para

En este mismo plano de las reticencias, cabe situar la multitud de dificultades para que las autoridades laborales puedan velar por el cumplimiento de la normativa vigente ${ }^{97}$, ya que el control debe efectuarse con respeto del derecho a la inviolabilidad del domicilio, sometiendo la actuación de la ITSS a las facultades y límites contemplados en el artículo 5.1 de la Ley 42/1997, ordenadora de la ITSS que dispone que "si el centro sometido a inspección coincidiese con el domicilio de la persona física afectada, deberán obtener su expreso consentimiento o, en su defecto, la oportuna autorización judicial". Por tanto, los únicos títulos habilitantes para la entrada en el domicilio son el consentimiento del titular o la autorización judicial. En el caso de que la ITSS quiera verificar el cumplimiento de la nueva normativa sobre trabajo doméstico con una inspección en un domicilio particular, el domicilio sería tendría la consideración de centro de trabajo, pero únicamente durante las horas que realiza el trabajo el empleado del hogar y, de no mediar consentimiento expreso y salvo que exista orden judicial, la ITSS, no podrá entrar en el citado domicilio. De ahí que las empleadas de hogar que se deciden a quejarse -la falta de quejas es otra de las características del colectivo- se suelen enfrentar a la negativa de inspectores laborales a intervenir en un terreno que se considera privado y respecto del que no se articulan ni planifican campañas de promoción y/o vigilancia del cumplimiento de las normas laborales ${ }^{98}$. De este modo, la tutela de la inviolabilidad domiciliaria y la intimidad personal (ex art. $18 \mathrm{CE}$ ) sirven de parapeto, y no deberían, para impedir "la aplicación de las normas laborales y de los derechos constitucionales que van a resultar incompatibles con la aplicación de determinadas medidas preventivas, especialmente como indicamos, la dificultad de compatibilizar el control de la autoridad laboral del cumplimiento de las normas de prevención, con el respeto a la intimidad y la inviolabilidad del domicilio ${ }^{99}$ ”.

Básicamente, se asiste a un conflicto entre derechos fundamentales: la empleada de

${ }^{97}$ El art. 17.2 Convenio 189 prevé que "todo miembro deberá formular y poner en práctica medidas relativas a la inspección del trabajo, la aplicación de las normas y las sanciones, prestado debida atención a las características especiales del trabajo doméstico, en conformidad con la legislación nacional”.

98 De fundamental lectura en este caso es el documento OIT: La inspección del trabajo y otros mecanismos de cumplimiento en el sector del trabajo doméstico: Guía introductoria, OIT, 2016.

${ }^{99}$ Ídem, pp. 100-104. 
hogar como ciudadana que es tiene derecho fundamental a la integridad física y moral (art. $15 \mathrm{CE}$ ) que, al entrar en conflicto con el también derecho fundamental de la inviolabilidad del domicilio (art. $18 \mathrm{CE}$ ) en este caso del empleador titular del hogar familiar en el que se prestan los servicios. Conflicto que ni es nuevo ni desconocemos cómo puede solucionarse en el marco constitucional contemporáneo: a través del juicio de ponderación y en aplicación de principios como el de proporcionalidad y razonabilidad. En definitiva, dado que existen condicionantes insoslayables a la acción de la ITSS que se traducen en que, en la práctica, se limiten a hacer las comprobaciones que puedan realizar sin pasar del umbral de la puerta del domicilio del empleador, es preciso, simplificar y agilizar lo máximo posible "el procedimiento dirigido a la obtención de la orden judicial, a fin de que puedan realizar un control efectivo y eficaz de las condiciones laborales también en este ámbito de trabajo ${ }^{100 ” . ~}$

\section{b. De las resistencias infranqueables}

Ya en el plano de las resistencias, más costosas de superar por lo que suponen de oposición o protesta frente al cambio que suponen, es posible encontrar dos principales: la referida a la exclusión del trabajo doméstico de la aplicación de la Ley de Prevención de Riesgos Laborales (LPRL) y de la protección por desempleo. Sendas exclusiones representan una merma de considerable repercusión en el marco protector del trabajo doméstico y se encuentran en el epicentro de todos los problemas de ratificación ${ }^{101}$.

Respecto de lo primero, se conculca el mandato de la OIT según el cual "todo trabajador doméstico tiene derecho a un entorno de trabajo seguro y saludable. Todo Miembro, en conformidad con la legislación y la práctica nacionales, deberá adoptar medidas eficaces, teniendo debidamente en cuenta las características especificadas del trabajo doméstico, a fin de asegurar la seguridad y salud en el trabajo de los trabajadores domésticos” (ex art. 13 Convenio 189). España ha optado por dejar fuera del ámbito objetivo de aplicación de la LPRL al trabajo doméstico lo que supone "un retroceso en la regulación de la Seguridad Laboral en el sector ${ }^{102}$ ". Esta exclusión encuentra su fundamento tanto por la especial interrelación que en el trabajo de servicio del hogar familiar existe entre las condiciones laborales del trabajador y las del empleador, como por las peculiaridades del lugar donde se presta el trabajo que complican la aplicación de determinadas previsiones normativas generales en materia de seguridad y salud en el

${ }^{100}$ MIÑARRO YANINI, M.: "Formas esclavas de trabajo y servicio del hogar familiar: delimitación conceptual, problemática específica y propuestas”, op. cit, p. 88.

${ }^{101}$ Arts. 13 y 14 sobre salud y seguridad y sobre la protección de la seguridad social, respectivamente.

102 GARCIA VALVERDE, M. ${ }^{a}$ D.: "Una exclusión "particular" de la Ley de prevención de riesgos: el servicio del hogar familiar”, en ESCUDERO RODRIGUEZ, R.: (coord..): La ley de prevención de riesgos laborales: XIV jornadas universitarias andaluzas de derecho del trabajo y relaciones laborales, Consejo Andaluz de Relaciones Laborales, 1996, p. 178. 
trabajo $^{103}$. Pero esta justificación carece de fundamento ya que existen otras figuras tales como el trabajo a domicilio que no han sido excluidos ${ }^{104}$. Y, sin embargo, los riesgos laborales aumentan por el hecho de que "los hogares son ambientes que no están designados ni regulados en un principio para constituir lugares de trabajo y por ello, a diferencia de la industria, no están sujetos a una evaluación de riesgos o a los requisitos necesarios para obtener licencias ${ }^{105}$ ". Probablemente, como se ha apuntado acertadamente, "la solución más viable hubiese sido (...) que el legislador hubiera optado por aplicar la normativa contenida en la LPRL salvo en determinadas cuestiones en las que se recurriría a una normativa reglamentaria específica para solventar aquellos aspectos que no fueran compatibles con las peculiaridades de la relación laboral especial. A este respecto, se apuntan otras posibles soluciones, tales como las que arbitra cierto sector doctrinal referidas a la posibilidad de mantener este tipo de relación al margen del ámbito de aplicación de la LPRL y haber previsto una futura regulación reglamentaria ${ }^{106}$,. A nadie escapa el hecho de que el trabajo doméstico entrañe riesgos específicos que requieren del correspondiente desarrollo reglamentario, aunque por razones culturales se minusvalora su existencia ${ }^{107}$, y la propia OIT en el informe de la Comisión de Expertos en aplicación de las normas internaciones del trabajo 2019108, con ocasión de las observaciones de la UGT sobre exclusión de las trabajadoras

103 PÉREZ DE LOS COBOS ORIHUEL, F.: "La Directiva marco sobre medidas de seguridad y salud de los trabajadores en el trabajo y la adaptación del Ordenamiento español", Relaciones Laborales, $\mathrm{n}^{\circ}$ 8, 1991. p. 50, al referirse al fundamento de exclusión de este colectivo en la norma comunitaria conforme con lo dispuesto en el art. 3 de la Directiva 89/391/CEE de 12 de junio, relativa a la aplicación de medidas para promover la mejora de la seguridad y de la salud de los trabajadores en el trabajo, conocida como Directiva marco.

${ }^{104}$ RAMÍREZ MARTÍNEZ, J. M.: “La relación especial de trabajo al servicio del hogar familiar”, en VVAA: Trabajo subordinado y trabajo autónomo en la delimitación de la frontera del derecho del trabajo, Madrid, 1990, p. 48.

105 OIT: La inspección del trabajo y otros mecanismos de cumplimiento en el sector del trabajo doméstico: Guía introductoria, op. cit., p. 11.

106 SANZ SAEZ, C.: "La discriminación en contra de las empleadas de hogar como forma de manifestación de las discriminaciones múltiples”, op. cit., pp. 99-104.

107 TORADA, R. y MORENO, N.: "Salud laboral y género", en VVAA.: Mujer y trabajo, Problemática actual, Ed. Germania, 2001. En todo caso, la exclusión de la LPRL viene referida a la relación de las empleadas de hogar y no incluiría a quienes prestan su trabajo por cuenta de empresas de servicios o en el Servicio de Ayuda a Domicilio (SAD) de la Ley de Dependencia. En el SAD el cuidado personal va unido a las tareas domésticas propias de una empleada de hogar, especialmente en el caso de quienes atienden personas en situación de dependencia, los riesgos son los mismos en ambos casos: caídas, golpes con objetos, trastornos musculoesqueléticos derivados de movimientos repetitivos o posturas de trabajo inadecuadas, cortes, atrapamientos, quemaduras, dermatosis, alergias respiratorias e incluso riesgos particulares del hogar en que se desarrolla el trabajo. Sin embargo, el derecho a la intimidad, como el resto de los derechos fundamentales, comprendemos que tiene límites, algunos establecidos por la propia Constitución y otros derivados de la necesidad de proteger otros derechos u otros bienes constitucionalmente protegidos. Más detalles en FUNDACION PARA LA PREVENCION DE RIESGOS LABORALES UGT: La Guía de buenas prácticas para la Prevención de Riesgos en la Ayuda a Domicilio, que recoge de manera sistemática los que se pueden producir. Las Mutuas tienen editados manuales y guías de prevención para los trabajos de limpieza y manejo de cargas, así como los riesgos psicosociales, aplicables al empleo de hogar.

108 OIT: Aplicación de las normas internacionales del trabajo, 2019, Informe de la Comisión de Expertos en Aplicación de Convenios y Recomendaciones, Informe III (Parte A), OIT, 2019, p. 643. 
domésticas de la LPRL, recuerda al Estado español que "las personas trabajadoras domésticas migrantes son particularmente vulnerables a abusos y explotación [y por ello] la Comisión pide al Gobierno que indique las medidas tomadas con miras a (...) ii) garantizar que los mecanismos de denuncia existentes sean eficaces y accesibles. Además, recordando que más de la mitad de los extranjeros empleados en España trabajan en el servicio doméstico, la Comisión solicita información sobre las denuncias presentadas por los trabajadores domésticos, las investigaciones realizadas y las sanciones impuestas”.

Respecto de la segunda de las exclusiones referidas, se deja fuera de la protección por desempleo a este sector -bajo sospechas de algún tipo de fraude encubierto en la relación de confianza que lo caracteriza- conculcando el mandato de la OIT de "asegurar que los trabajadores domésticos disfruten de condiciones no menos favorables que las condiciones aplicables a los trabajadores en general con respecto a la protección de la seguridad social” (ex art. 14 Convenio 189). La ya referida DA $2^{\text {a }}$ RD 1620/2011 preveía, además, que la acción protectora del Sistema Especial para Empleados de Hogar (SEEH) "no comprenderá la correspondiente al desempleo. Eso se entiende sin perjuicio de las iniciativas que puedan establecerse con respecto a esta cuestión en el marco de la renovación de la relación laboral de carácter especial del servicio del hogar familiar". Dentro del mandato dirigido al grupo de expertos antes adelantado, se preveía que se informase también respecto de la creación de un mecanismo de protección por desempleo para este colectivo “adaptado a las peculiaridades de la actividad del servicio del hogar familiar que garantice los principios de contributividad, solidaridad y sostenibilidad financiera”. La ausencia de la protección por desempleo -ya contenida en el Régimen Especial de Empleados de Hogar (REEH), antes de ser integrado en el RGSS ${ }^{109}$ - choca ahora, sin embargo, con la progresiva extensión de la protección por desempleo a colectivos de trabajadores por cuenta ajena que han estado o están aún hoy insertos en regímenes especiales y que antes carecían de esta previsión ${ }^{110}$. Esta falta de cobertura implica un grave perjuicio para las empleadas de hogar que, por el momento, permanece tal cual sin que parezca próxima su inclusión (DA 39a.3. f. Ley 27/2011 $\left.{ }^{111}\right)^{112}$.

\footnotetext{
${ }^{109} \mathrm{Y}$ que encontraba su soporte jurídico en el artículo 3.2 de la Ley 31/1984, de 2 de agosto, de protección por desempleo, según el cual aquélla alcanza a todos los trabajadores por cuenta ajena, haciendo depender dicha inclusión del hecho de estar contemplada esta contingencia en los regímenes especiales.

${ }^{110}$ Más detalles en SANZ SAEZ, C.: La protección social de las empleadas de hogar. La desaparición del Régimen Especial de la seguridad Social y su integración en el Régimen General como Sistema Espacial: análisis actual y de futuro, Bomarzo, 2017.

111 Ley 27/2011, de 1 de agosto, sobre actualización, adecuación y modernización del sistema de Seguridad Social cuya DA 39a.3. f prevé que "la acción protectora del Sistema especial para Empleados de Hogar no comprenderá la correspondiente al desempleo. Eso se entiende sin perjuicio de las iniciativas que puedan establecerse con respecto a esta cuestión en el marco de la renovación de la relación laboral de carácter especial del servicio del hogar familiar”.

112 Otra de las promesas incumplidas es la equiparación en materia de cotización por salarios reales y en materia de cobertura respecto de sectores que continúa siendo una realidad inmaterial máxime "gracias" a
} 
Las eventuales modificaciones que deberían haberse producido en todos los sentidos referidos e implementado antes de finales del año 2013, según el propio RD 27/2011 y como paso previo a la ratificación del Convenio 189 OIT no se han materializado por el momento. De hecho, ni el referido grupo de expertos llegó a constituirse, ni consta que esté previsto hacerlo ni a medio ni a largo plazo. Es más, en octubre de 2013 se presentó una proposición no de ley para la ratificación del Convenio que fue aprobada por unanimidad en la Comisión de Empleo y Seguridad Social del Parlamento instando al Gobierno a reevaluar las razones para su no ratificación y plantearse, en consecuencia, la necesidad de su ratificación y la adopción de la legislación pertinente. A pesar de este acuerdo, del tiempo transcurrido y de que países del entorno (como Italia y Alemania) ya habían ratificado el Convenio, el Parlamento español no siguió trabajando en esta línea y ninguna otra medida fue adoptada en este sentido lo que es buena muestra del desinterés político por el tema. En definitiva, ni el Gobierno del PP, ni el del PSOE fruto de la exitosa moción de censura contra aquél, han considerado la importancia y oportunidad de ratificar de momento dicho convenio, alegando las recurrentes y burdas excusas expuestas líneas atrás, esto es, la complicada intervención en los hogares familiares, la dificultad de prevenir riesgos laborales en este sector y de introducir la prestación de desempleo en un momento difícil para las arcas de la Seguridad Social. Y ello pese a que, no podemos dejar de señalar, en este sentido, que hasta la Unión Europea ha instado a los Estados miembros de la Unión a que procedan a su ratificación ${ }^{113}$.

\section{ALGUNAS REFLEXIONES FINALES}

Según datos de 2015, fruto de la aprobación del RD 1620/2011, el número de personas afiliadas aumentó casi de forma inmediata (de 291.670 en 2010 a 424.423 en 2015), pero, al mismo tiempo, descendieron las ocupadas (de 735.400 en 2010 a 614.200 en $2015^{114}$ ), sin haber sido posible perpetuar la línea ascendente de regularización en el sector en los años posteriores y mucho menos cumplir el objetivo de "aflorar" trabajo informal, sobre todo, por el incremento de los costes que la afiliación supone para los empleadores (las familias).

la enmienda 6777 presentada por el grupo parlamentario popular al proyecto de PGE 2019 y acatada por el PSOE y que retrasa de forma irreversible el proyecto de equiparación hasta el 2024.

${ }^{113}$ Para ello, la Comisión Europea presentó el 21 de marzo de 2013 una propuesta de Decisión del Consejo que autoriza a los Estados miembros a la ratificación del Convenio. Así, son diversas las instituciones sociales y los Grupos Parlamentarios en España que consideran la necesidad de iniciar los trámites necesarios para la ratificación del Convenio, especialmente tras la Decisión del Consejo de la UE de 28 de enero de 2014, publicada el 1 de febrero de 2014. De esta forma, el Consejo de la Unión ha seguido los pasos dados por la Comisión Europea y el Parlamento Europeo a favor del Convenio, que han instado también a los Estados miembros a ratificarlo y aplicarlo con urgencia. Esta posición de la UE es coherente con los contenidos de la Carta Social Europea y con los de la Carta de Derechos Fundamentales de la Unión, especialmente en lo que se refiere a "unas condiciones de trabajo justas y equitativas y a la protección social.

${ }^{114}$ Según datos EPA e INE 
Siendo cierto y verdad que la aprobación de esta norma supuso en España un paso considerable en el afianzamiento de los derechos laborales de las trabajadoras del sector doméstico, es fundamental mantener su presencia en la agenda política para evitar posibles estancamientos y enfrentar los desafíos que aún quedan pendientes como la ratificación del Convenio 189. Y para ello resulta crucial, además, dotar de mayor protección colectiva de los empleados domésticos. Afortunadamente, desde hace un tiempo se vienen formando asociaciones de trabajadores domésticos a fin de canalizar sus demandas y denuncias, y los sindicatos también les han dado cobertura, integrándolos en su estructura y promoviendo acciones para su promoción y apoyo. Es más, se dice que la no ratificación del Convenio 189 está en el origen del movimiento asociativo reivindicativo.

La no ratificación del Convenio 189 está funcionando, de facto, como el elemento actual de unidad fundamental del movimiento de defensa de los derechos de las empleadas de hogar que han centrado sus reivindicaciones en la necesidad de incorporar la protección por desempleo, pero también en la necesidad de fomentar, desde las instituciones públicas, el asociacionismo y sindicación de las empleadas de hogar o de promover organizaciones de empleadores e intermediarios con los que poder negociar sus condiciones laborales ${ }^{115}$. No cabe la menor duda que tanto la descentralización

115 Sólo en unos cuantos países, como Francia e Italia, existen federaciones de empleadores de trabajadores domésticos que permiten llevar a cabo negociaciones colectivas. En Italia tres sindicatos negociaron un primer acuerdo colectivo con la Federación Nacional del Clero Italiano y dos asociaciones patronales/de empleadores en 1974. Durante las siguientes cuatro décadas los empleadores se organizaron para establecer sus propias organizaciones de representación: la Associazione Nazionale Famiglie Datori di Lavoro Domestico (DOMINA) y la Federazione Italiana Datori di Lavoro Domestico (FIDALDO). La FIDALDO firmó el correspondiente acuerdo en 1996 y la DOMINA lo hizo en 2001. El acuerdo vigente en la actualidad fue firmado en 2013 e incluye tasas de salarios, períodos de descanso, vacaciones pagadas, subsidio de enfermedad e indemnización por despido. El acuerdo carece de aplicación universal, ya que obliga únicamente a los empleadores miembros de la DOMINA o la FIDALDO, o a aquellos que firmaron contratos que remitieran explícita o implícitamente a los acuerdos de negociación. Cuando los trabajadores no cubiertos formalmente por estos contratos acuden a los tribunales, las disposiciones sobre salarios y seguridad social son las normas en que se basan los jueces para dictar sentencia. A pesar de las limitaciones mencionadas, en el sector del trabajo doméstico la situación ha mejorado significativamente en los últimos quince años y ha aumentado considerablemente el número de trabajadores que ha firmado contratos tipo. Más detalles en OIT: Italy Case Study: New iniciatives, organization forms and sources of power for articulating (collective) labour interest in the domestic work sector, Servicio de Mercados Inclusivos, relaciones Laborales y Condiciones de Trabajo, Departamento WORKQUALITY, Ginebra, no publicado pero reflejado en OIT: Voz y representación de los trabajadores domésticos a través de la organización, Nota informativa 8, OIT.

En otros países como Francia, las relaciones triangulares han dado lugar a una serie de acuerdos colectivos con diferentes organizaciones de empleadores, que actuaban en representación de los cabeza de familia empleadores o de intermediarios y organismos (públicos o privados). El primero de estos acuerdos fue firmado en 1999 por las siguientes confederaciones sindicales: Fédération des particuliers employeurs de France (FEPEM), Confédération française démocratique du travail (CFDT), Confédération Générale du Travail (CGT), Confédération française des travailleurs chrétiens (CFTC) y Force Ouvrière (FO), y beneficiaba únicamente a trabajadores remunerados por particulares y empleados por los diferentes hogares (68 \% de la mano de obra). Se firmaron dos acuerdos más: uno en 2012, que firmaron seis sindicatos y dos organizaciones de empleadores, y beneficiaba a trabajadores domésticos colocados en viviendas de particulares por intermediarios sin fines lucrativos; y el segundo, firmado en 
como el aislamiento de las trabajadoras domésticas y el hecho de que, normalmente, no tengan compañeros de trabajo, constituyen serias dificultades al ejercicio de sus derechos colectivos de asociación, representación y negociación colectiva. Cierto es que el ordenamiento jurídico español no lo prohíbe, pero sí que las “dificultades para su ejercicio, no han sido resueltas por la norma reglamentaria con una adaptación a las condiciones de los trabajadores de este sector ${ }^{116 ” . ~ Y ~ p r e c i s a m e n t e ~ p o r ~ e l l o ~ e s ~ n e c e s a r i o ~}$ aumentar la implicación política en este sentido de cara a lograr un mayor peso colectivo que les dé más fuerza, alentando otros derechos como el de la negociación colectiva. Se considera que, sin desmerecer otro tipo de organizaciones, "los sindicatos son los sujetos colectivos que deberían asumir prioritariamente esta importante función, por ser estructuras ya existentes, por la relevancia que se les reconoce, por las funciones que están llamados a desarrollar y por tener capacidad de unificar las reivindicaciones de los trabajadores del sector, y por tanto, de actuar con mayor fuerza colectiva ${ }^{117,}$. Y es que de la ratificación y la aplicación el este Convenio se ha dicho que es imprescindible para la acción sindical en favor de las trabajadoras y los trabajadores domésticos, incluyendo el brindarles el “derecho por ley a sindicalizarse ${ }^{118 ”}$.

En otro orden de cosas, quiere hacerse una breve referencia final al hecho de que

2014 por tres sindicatos y dos organizaciones de empleadores en representación de empresas privadas, que beneficiaba a trabajadores domésticos empleados por empresas privadas. Considerados conjuntamente, estos acuerdos abarcan la mayor parte del sector del trabajo doméstico. Más detalles en OIT: France Case Study: New iniciatives, organization forms and sources of power for articulating (collective) labour interest in the domestic work sector, Servicio de Mercados Inclusivos, relaciones Laborales y Condiciones de Trabajo, Departamento WORKQUALITY, Ginebra, no publicado pero reflejado en OIT: Voz y representación de los trabajadores domésticos a través de la organización, Nota informativa 8, OIT.

116 SANZ SAEZ, C.: "Derechos colectivos y empleadas del hogar: reformas jurídicas inaplazables para un trabajo decente del trabajo doméstico en España”, op. cit., p. 19. De hecho, a la Recomendación 201, en su art. 2 contempla que "al adoptar medidas para asegurar que los trabajadores domésticos disfruten de la libertad sindical y del reconocimiento efectivo del derecho de negociación colectiva, los Miembros deberían: a) identificar y suprimir las restricciones legislativas o administrativas u otros obstáculos al ejercicio del derecho de los trabajadores domésticos a constituir sus propias organizaciones o a afiliarse a las organizaciones de trabajadores que estimen convenientes, y al derecho de las organizaciones de trabajadores domésticos a afiliarse a organizaciones, federaciones y confederaciones de trabajadores; y b) contemplar la posibilidad de adoptar o apoyar medidas destinadas a fortalecer la capacidad de las organizaciones de trabajadores y de empleadores, las organizaciones que representen a los trabajadores domésticos y las organizaciones que representen a los empleadores de trabajadores domésticos, con el fin de promover de forma efectiva los intereses de sus miembros, a condición de que se proteja en todo momento la independencia y la autonomía de dichas organizaciones, en conformidad con la legislación”.

117 MIÑARRO YANINI, M.: "Formas esclavas de trabajo y servicio del hogar familiar: delimitación conceptual, problemática específica y propuestas”, op. cit., p. 87.

118 OIT: En pro del trabajo decente para las trabajadoras y los trabajadores domésticos: Un manual para sindicalistas destinado a promover el Convenio $n^{\circ} .189$ de la OIT y el empoderamiento de las trabajadoras y los trabajadores domésticos, OIT, 2012. Se considera que, sin desmerecer otro tipo de organizaciones, "los sindicatos son los sujetos colectivos que deberían asumir prioritariamente esta importante función, por ser estructuras ya existentes, por la relevancia que se les reconoce, por las funciones que están llamados a desarrollar y por tener capacidad de unificar las reivindicaciones de los trabajadores del sector, y por tanto, de actuar con mayor fuerza colectiva”, en MIÑARRO YANINI, M.: "Formas esclavas de trabajo y servicio del hogar familiar: delimitación conceptual, problemática específica y propuestas”, op. cit., p. 87. 
España que siempre ha llevado como bandera el ser uno de los países que más convenios ha ratificado ${ }^{119}$, lleva meses sin hacerlo ${ }^{120}$. Ello bien pudiera deberse al momento de inestabilidad política que se vive en nuestro país, pero conviene recordar en estos momentos de tanta incertidumbre que las normas internacionales del trabajo son instrumentos universales adoptados por la comunidad internacional que reflejan valores y principios comunes sobre los asuntos relacionados con el trabajo y, aunque los Estados Miembros pueden elegir entre ratificar o no ratificar un Convenio determinado, la OIT también considera importante seguir la evolución producida en los países que no hayan ratificado determinados convenios ${ }^{121}$. Pero, sobre todo, "las normas internacionales del trabajo son instrumentos para los gobiernos que, en consulta con los empleadores y los trabajadores, se proponen elaborar y aplicar una legislación laboral, al igual que políticas sociales que estén de conformidad con las normas aceptadas internacionalmente $^{122}$ ". Por ello, para un gran número de países, este proceso se inicia con la decisión de considerar la posibilidad de ratificación de un convenio de la OIT. Pero también ocurre a menudo que algunos países o bien proceden al examen y, si es necesario, a la revisión de su legislación y de sus políticas para adecuarlas instrumento que desean ratificar antes de hacerlo o bien deciden no ratificar un determinado convenio pero, sin embargo, adecuan su legislación al convenio de que se trate. En estos últimos dos casos, lo que suelen hacer los países es utilizar "las normas de la OIT como modelos para elaborar su legislación y formular directrices de política. Incluso hay países que ratifican los convenios de la OIT muy rápidamente y luego tratan de adecuar su legislación y sus prácticas nacionales a ese instrumento ${ }^{123}$ ".

\footnotetext{
119 Grosso modo, España tiene ratificados los 8 convenios fundamentales (C029 sobre trabajo forzoso, C087 sobre libertad sindical, C098 sobre derecho de sindicación y negociación colectiva, C100 sobre igualdad de remuneración, C105 sobre abolición del trabajo forzoso, C111 sobre discriminación (empleo y ocupación), C138 sobre edad mínima y C182 sobre las peores formas de trabajo infantil); los 4 convenios de gobernanza o prioritarios (C081 sobre la inspección de trabajo, C122 sobre la política de empleo, C129 sobre la inspección de trabajo (agricultura) y C144 sobre la consulta tripartita (normas internacionales del trabajo)); y 121 convenios técnicos de los 177 existentes a fecha de cierre de esta aportación.

${ }^{120}$ Más concretamente, desde septiembre de 2017 fecha en que se ratificó el Protocolo de 2014 relativo al Convenio sobre el trabajo forzoso.

${ }^{121}$ Por ello, en virtud del art. 19 de la Constitución de la OIT, los Estados Miembros están obligados a informar con intervalos regulares, a solicitud del Consejo de Administración, de las medidas que han adoptado para dar efecto a las disposiciones de algunos convenios o recomendaciones, y para indicar cualquier obstáculo que les impidiera o retrasara la ratificación de un determinado convenio. En virtud del citado precepto, la Comisión de Expertos publica cada año un estudio general exhaustivo sobre la legislación y la práctica nacionales en los Estados Miembros, sobre determinados convenios o recomendaciones escogidos por el Consejo de Administración. Los estudios generales se realizan, sobre todo, sobre la base de las memorias recibidas de los Estados Miembros y de las informaciones comunicadas por las organizaciones de empleadores y de trabajadores, información que permite a la Comisión de Expertos el examen del impacto de los convenios y de las recomendaciones, el análisis de las dificultades y de los obstáculos para su aplicación que señalan los gobiernos y la identificación de los medios para superar esos obstáculos. Más detalles en OIT: Las reglas del juego. Una introducción a la actividad normativa de la Organización Internacional del Trabajo, Edición del Centenario, 2019.

122 Ídem, p. 25.

${ }^{123}$ Ídem.
} 
Sea como fuere, España no ha ratificado el Convenio 189 pese a haber dado los primeros pasos para adecuar su normativa interna nada más aprobarse en mismo y antes de que entrara en vigor. Da la sensación de tratarse de un Convenio que ha caído en el olvido y que, salvo la insistencia recurrente del todavía incipiente movimiento asociativo, ha sido imbuida por una desidia que imposibilita la acción política tan necesaria como ha intentado ponerse de manifiesto en las líneas precedentes. Que España podría haber ratificado el Convenio 189 desde el día siguiente a su aprobación y haber llevado a cabo las modificaciones/adaptaciones normativas precisas sin solución de continuidad, nadie lo pone en duda. Pero no se ha optado por esa posibilidad y, en estos momentos de impasse, el futuro se presenta incierto. Quizás hayan ganado el pulso excusas como las abordadas en los epígrafes anteriores pero, debe ponernos sobre aviso el hecho de que esté ocurriendo lo mismo con convenios como el C175 sobre trabajo a tiempo parcial, el C177 sobre trabajo a domicilio y el C183 sobre la protección de la maternidad. O es mucha coincidencia o la casualidad ha querido que se trate, en todos estos casos, de convenios relacionados con el trabajo de las mujeres y las múltiples brechas de género que en el mundo del trabajo persisten y respecto de las cuales queda tantísimo por hacer en España. Allá cada uno con sus propias conclusiones...

\section{BIBLIOGRAFIA}

- AGUADO, E.: “Segregación ocupacional: una mirada crítica a la participación tamizada de las mujeres en el empleo, Revista Gaceta Sindical, nº 31, 2018.

- ALFONSO, C.L.: "Desigualdades laborales: la brecha salarial desde la vertiente normativa, Revista Gaceta Sindical, $n^{\circ}$ 31, 2018.

- ARAGON GOMEZ, C.: "El impacto de la brecha salarial en la acción protectora del sistema de Seguridad Social”, Documentación Laboral, nº 115, 2018.

- BALLESTER PASTOR, Ma . A.: "La discriminación retributiva por razón de sexo en la Unión Europea”, Documentación Laboral, n 115, 2018.

- BLASCO RASERO, C.: "El sistema especial de empleados de hogar y el proceso de homogeneización”, Revista Doctrinal Aranzadi Social, nº 4, 2013.

- BLAZQUEZ AGUADO, E. M. ${ }^{a}$ (Dir.): Los ODS como punto de partida para el fomento de la calidad del empleo femenino, Dykinson, 2018.

- "La igualdad de género como objetivo de desarrollo sostenible",

Revista Femeris, vol. 2, n 1, Universidad Carlos III de Madrid, 2017.

- BUDIG, M.J. Y MISRA, J.: "Los salarios de la economía del cuidado en comparación internacional”, Revista Internacional del Trabajo, vol. 129, nº 4, 2010.

- CAÑABATE PEREZ, J.: ““Servir es distinto a trabajar”: Potestad del cabeza de familia vs. Protección social del servicio doméstico en la dictadura franquista”, en GARCIA GONZALEZ, G. Y ESPUGNY I TOMAS, Mª. J. (coord.): Relaciones laborales y empleados del hogar: reflexiones jurídicas, Dykinson, 2014. 
- CARRASCO, C.: "La economía del cuidado: planteamiento actual y desafíos pendientes”, Revista de Economía Crítica, nº 11, 2011.

- CARRASCO BENGOA, C.: "El cuidado como eje vertebrador de una nueva economía”, Cuadernos de Relaciones Laborales, vol. 31, nº ${ }^{\circ} 1,2013$.

- CEBRIAN, I. Y MORENO, G.: "Las brechas de la precariedad. Empleo y ocupaciones”, revista Gaceta Sindical, n 31, 2018.

- DIAZ MARTINEZ, C. Y SIMÓ-NOGUERA, C.X. (coord..): Brecha salarial y brecha de cuidados, Tirant humanidades, 2016.

- DURAN HERAS, Ma . A.: El trabajo no remunerado en la economía global, Fundación BBVA, 2012.

- EZQUERRA, S.: “Crisis de los cuidados y crisis sistémica: la reproducción como pilar de la economía llamada real”, Revista Investigaciones Feministas, vol. 2, 2011.

- FERNANDEZ COLLADOS, Ma . B.: "Los cuidados en el entorno familiar más de una década después: los vaivenes en su regulación, su aplicación por la doctrina judicial y sus efectos en materia de igualdad”, revista Española de Derecho del Trabajo, $\mathrm{n}^{\circ}$ 210, 2018.

- FERNANDEZ ORRICO, F.J.: "Primer intento de mejora en la gestión del sistema especial para empleados de hogar por RDL 29/2012, de 28 de diciembre”, Revista de Justicia Laboral, $\mathrm{n}^{\circ}$ 53, 2013.

- GALVEZ MUÑOZ, G.: La economía de los cuidados, Deculturas, 2016.

- GALVEZ MUÑOZ, L. Y RODRIGUEZ MADROÑO, P.: "La desigualdad de género en las crisis económicas”, Revista Investigaciones Feministas, vol. 2, 2011.

- GALVEZ MUÑOZ, G. Y TORRES LOPEZ, J.: Desiguales. Mujeres y hombres en la crisis financiera, Icaria, 2010.

- GARCIA GONZALEZ, G.: "La integración del régimen especial de empleados de hogar en el régimen general: logros y retos de futuro, Revista doctrinal Aranzadi Social, $\mathrm{n}^{\circ}$ 8, 2011.

- GARCIA SEDANO, T.: "En las antípodas del trabajo decente: el trabajo forzoso, Revista Lan Harremanak, n 39, 2018.

- GRAU PINEDA, C. y DOMINGUEZ-MUJICA, J.: "La persistencia de mujeres inmigradas en el servicio doméstico en España en tiempos de recesión económica: datos para la reflexión”, Revista de derecho migratorio y extranjería, nº 40, 2015.

- LOPEZ AHUMADA, E.: “Trabajo informal, transición a la formalidad e inclusión social en Latinoamérica”, Revista de Estudios Latinoamericanos de Relaciones Laborales y Protección Social, nº 3, 2017.

- LOUSADA AROCHENA, J.F Y RON LATAS, R.P.: "La integración del trabajo decente de la Organización Internacional del Trabajo dentro de los objetivos de desarrollo sostenible de Naciones Unidas”, Revista Española de Derecho del Trabajo, $\mathrm{n}^{0}$ 211, 2018. 
- LOUSADA AROCHENA, J.F.: "La igualdad retributiva de mujeres y hombres en la acción de Naciones Unidas y la Organización Internacional del Trabajo", Documentación Laboral, $\mathrm{n}^{\circ}$ 115, 2018.

- "Normativa internacional contra la explotación humana y laboral en el trabajo doméstico: la ONU y la OIT”, Lan Harremanak, nº 39, 2018.

- MARTINEZ I CASTELlS, A. Y CASANUEVA ARTIS, A.: "La crisis en femenino plural”, Revista de Economía Critica, nº 9, 2010.

- MESA MARRERO, C. (Dir.) y GRAU PINEDA, C. (Coord.): Mujeres, contratos y empresa desde la igualdad de género, Tirant lo Blanch, 2014.

- MIÑAMBRES PUIG, C.: "El nuevo régimen jurídico de los empleados de hogar familiar”, Revista española de Derecho del Trabajo, $\mathrm{n}^{\circ}$ 157, 2013.

- MIÑARRO YANINI, M.: "Formas esclavas de trabajo y servicio del hogar familiar: delimitación conceptual, problemática específica y propuestas”, Relaciones Laborales, $n^{\circ}$ 10, 2014.

- OELZ, M.: "El Convenio y la Recomendación de la OIT sobre las trabajadoras y los trabajadores domésticos. Una oportunidad para la justicia social”, Revista Internacional del Trabajo, vol. 133, $\mathrm{n}^{\mathrm{0}} 1$.

- OIT: Protección eficaz de los trabajadores domésticos: Guía para diseñar leyes laborales, OIT, 2012.

- OIT: Memoria sobre el trabajo decente, 1999.

- OIT: Resolución relativa al trabajo decente y la economía informal, adoptada en la $90^{a}$ reunión de la Conferencia Internacional del Trabajo, Ginebra, 2002.

- OIT: Guía práctica para la incorporación sistemática del empleo y el trabajo decente, Ginebra, 2008.

- OIT: Trabajo decente para los trabajadores domésticos, Informe IV, 99a reunión de la Conferencia Internacional del Trabajo, Ginebra, 2010.

- OIT: Protección eficaz de los trabajadores domésticos: guía para diseñar leyes laborales, Ginebra, 2012.

- OIT: Domestic workers across the world: Global and regional statistics and the extent of legal protection, Ginebra, 2013.

- OIT: La inspección del trabajo y otros mecanismos de cumplimiento en el sector del trabajo doméstico: Guía introductoria, OIT, 2016.

- OIT: Impacto de las reformas legislativas en el sector del empleo del hogar en España, Serie condiciones de trabajo y empleo, OIT, $\mathrm{n}^{\circ} 82$, 2016.

- OIT: Perspectivas sociales y del empleo en el mundo: tendencias del empleo femenino 2018, OIT, 2018.

- OIT: Aplicación de las normas internacionales del trabajo, 2019, Informe de la Comisión de Expertos en Aplicación de Convenios y Recomendaciones, Informe III (Parte A), OIT, 2019. 
- OIT: Las reglas del juego. Una introducción a la actividad normativa de la Organización Internacional del Trabajo, Edición del Centenario, 2019.

- ONU MUJERES: Hacer las promesas realidad: La igualdad de género en la Agenda 2030 para el desarrollo sostenible, ONU, 2018. Disponible en http://www.unwomen.org/es/digital-library/publications/2018/2/gender-equality-inthe-2030-agenda-for-sustainable-development-2018\#view

- OROZCO, A.: "Diagnóstico de la crisis y respuestas desde la economía feminista", Revista de Economía Critica, nº 9, 2010.

- PEREZ AlONSO, P. (Dir.): El derecho ante las formas contemporáneas de esclavitud, Tirant lo Blanch, 2017.

- PEREZ-BEDMAR, Ma . DE S.: "La relación laboral especial de empleados de hogar: aspectos laborales y de seguridad social”, revista jurídica de la UAM, n 23, 2011.

- PEREZ DEL PRADO, D.: "Una aproximación a los indicadores de cumplimiento de los ODS desde la perspectiva de género", Revista de Información Laboral, $\mathrm{n}^{\circ} 7$, 2018.

- PEREZ OROZCO, A.: "Amenaza tormenta: la crisis de los cuidados y la reorganización del sistema económico”, Revista de Economía Crítica, nº 5, 2006.

- POYATOS I MATAS, G.: "De la ética del cuidado feminizada a la ética del cuidado humanizada. A propósito de la cuestión prejudicial planteada por el Tribunal Superior de Justicia de Canarias respecto al "complemento por maternidad"”, Revista de Trabajo y Seguridad Social, CEF, nº 431, 2019.

- QUESADA SEGURA, R.: "La dignificación del trabajo doméstico: el Convenio no 189 de la Organización Internacional del Trabajo, 2011”, Revista General de Derecho del Trabajo y de la Seguridad Social, $n^{\circ}$ 27, 2011.

- RAMOS QUINTANA, M.I.: "La iniciativa mundial relativa a las mujeres en el trabajo”, Revista Trabajo y Derecho, nº 51, 2019.

- RODRIGUEZ CARDO, I. A.: "La relación laboral especial de los empleados de hogar”, Revista del Ministerio de Empleo y Seguridad Social, nº 118, 2015.

- RODRIGUEZ ESCANCIANO, S.: "La discriminación retributiva por causa del sexo y del género: factores desencadenantes y pautas de resolución, Documentación Laboral, $n^{\circ}$ 113, 2018.

- ROMERAL HERNANDEZ, J.: "El impacto del Convenio 189 de la OIT en las condiciones de trabajo de los empleados de hogar", Revista doctrinal Aranzadi Social, $\mathrm{n}^{\circ}$ 7, 2013.

- SANZ SAEZ, C.: "Derechos colectivos y empleadas del hogar: reformas jurídicas inaplazables para un trabajo decente del trabajo doméstico en España", comunicación presentada y seleccionada respecto de la conversación II "Trabajo decente para todos" en el Congreso Interuniversitario OIT sobre el futuro del trabajo, Sevilla, 7-8 febrero 2019. 
o "La discriminación en contra de las empleadas de hogar como forma de manifestación de las discriminaciones múltiples”, Revista de Derecho Social, $\mathrm{n}^{\circ}$ 83, 2018.

- La protección social de las empleadas de hogar. A desaparición definitiva del régimen especial de la seguridad social y su integración en el régimen general como sistema especial: análisis actual y de futuro, Bomarzo, 2017.

o Génesis y evolución del servicio doméstico, Comares, 2018.

- VVAA: "Percepción de las trabajadoras inmigrantes del servicio doméstico sobre los efectos de la regulación del sector en España”, Gaceta Sanitaria, 28 (2), 2014.

- VELA DIAZ, R.: "La promoción internacional de un trabajo decente para las personas empleadas de hogar: el Convenio 189 de la OIT sobre trabajadores domésticos”, revista del Ministerio de Empleo y Seguridad Social, nº 127, 2017. 